\title{
Positionality in a Postdigital Context
}

Why Is Postdigital Positionality a Matter for Everyone?

From isolation to online exhibitionism. From fluid identities to protected and unprotected characteristics. From technological dependence, inclusion, exclusion and indifference. From emancipation to exploitation. From medical attention to lack of healthcare. From opportunity to marginalisation. From free speech to censorship. From inviting to cancelling. These are just a few of the very broad dimensions that connect with individual positionality, in relation to digital devices, data and platforms, as they interact with each of our socioeconomic and sociocultural, as well sociomaterial and biological circumstances. Whilst referring to this landscape as postdigital, it is immediately accepted that such terminology is imperfect, but also useful, as it provides a basis for critical and open dialogue (Jandrić et al., 2018). More people than ever before are interacting across the virtual airing cupboard of the Internet, and all that it now connects with, as the pandemic has contributed to further altering this scene. It leaves individuals positioned differently to each other, but with collective questions too.

As humans have become routinely subject to rational forms of computer processing, data compilation, extraction and related deterministic discourse in many aspects of their lives, who they perceive themselves to be as subjective beings, can become either diminished, or extended. For Steve Fuller, 'human' is a normative category concerning what 'self-described' humans decide to include, or exclude (Fuller \& Jandrić, 2018). Fuller suggests that we might reach an agreement about the performance standards that a putative 'human' should meet that a 'non-human' does not meet. Braidotti in Posthuman Ecologies (2019) refers to the 'falsely universal' notion of the 'human' and 'of the system of moral values and human rights that rest upon it'. Braidotti applies a 'posthuman paradigm as an analytical tool for understanding the perspectival nature of knowledge and for drawing attention to the primacy of non-human influences in formative processes' (Braidotti, 2019). This has direct relevance for how a so-called non-human might be suitably acknowledged as a participant alongside humans in an inclusivity strategy, given that human data now passes between technological devices, as well as between humans and their own devices. 
However, other authors have pointed to how the identity of a human is constructed differently across different disciplinary fields too. As Mark Poster (1990) has observed, the discipline of computer science is identified through its relationship to the computer: 'identity remains part of the disciplinary protocol of the field, even if the actual object, the computer, changes significantly, even unrecognisably, in the course of the years' (Poster, 1990: 147). On this basis, it could be said that in the humanities, the subjective human content is emphasised, even if what it means to be human has changed alongside new, intimate digital and biological interactions with computers that we might debate via biodigital philosophy (Peters, Jandrić \& Hayes, 2021a). There are further questions too concerning the place of our human vitality amid global steps towards a circular bioeconomy (Peters, Jandrić \& Hayes, 2021b). These intermingle currently with public health and the effects of a global pandemic across society (Dingwall, Hoffman \& Staniland, 2013).

Gary Hall (2013) suggests that what has come to be called the digital humanities should not though, simply be perceived as a bringing together of computing and humanities, as if these were 'equivalent'. He suggests that it is necessary instead to maintain a distinction between digital computing and the humanities. More emphasis has been placed on 'direct, practical uses computer science can be put to in the humanities' to improve processes and operations. This is a one-way flow that imposes a particular rational logic from computer science on the humanities. There has been less discussion on what 'the humanities themselves bring to the understanding of computing' (Hall, 2013: 782). This argument has connection too with the treatment of technology on the one hand, as an efficient way to fix processes or enhance teaching in some HE policies, but the omission of the consequences of digital technologies on the other hand. It is no longer adequate to simply generate sets of policies that are isolated from each other, when there are complex implications for equality, diversity and inclusion.

McDonaldisation Values Humans as Rational Objects Not Postdigital Subjects

George Ritzer's (1993/2018) McDonaldisation thesis is one route towards placing the tensions between humanities and computing within a more global overview of recent political economic change and wider cultural activity. Adapted from Weber's theory of rationalisation (Weber, 1930) McDonaldisation demonstrates how humans came to be valued objectively, in a model that mimics the basic criteria on which fast food restaurants have become profitable. Digital developments simply become applied in rational, predictable, commercial agendas in this model, to increase efficiency and exercise greater control over 
employees. Computing capabilities then are merely tools adopted to improve performance standards for humans. New examples of McDonaldisation can be noticed as processes of globalisation and automation through technology have brought many forms of large-scale rationalisation into play in physical, online and augmented situations. However, the rationality underpinning the more traditional predigital examples of McDonaldisation appear to be meeting new tensions in postdigital society that can yield unexpected, irrational outcomes (Ritzer, Jandrić \& Hayes, 2018). These were particularly apparent in the analysis of McPolicy statements that began to lose meaning as linguistic constructions, not people, were repeatedly attributed with human tasks (Hayes, 2019). Reflecting on biodigital philosophy (Peters, Jandrić \& Hayes, 2021a), we might also debate possible shifts to come from former models simply based on technology to support rational, human production and consumption.

I have previously discussed how a persistent tendency in recent decades to reorganise and reform education through what sounds like a 'common sense' logic in policy discourse (McPolicy) has effectively seen humans writing themselves out of their own roles (Hayes, 2019a). Given predictions of a 4th Industrial Revolution (Schwab, 2017, Peters, Jandrić \& Hayes, 2018, WEF, 2019) that threatens people with mass unemployment, I pointed out a curious pattern of assigning human characteristics to technologies in policy language and irrationally attributing human labour to machines and not to people (Hayes \& Bartholomew, 2015). Alongside much reform and disorientation concerning the purposes of education, as well as a rising 'therapy culture' (Furedi, 2004) the potential for humans to be diminished by Artificial Intelligence (AI) presents a real threat (Seldon, 2020: 1).

\subsection{Evolutionary Technological and Cultural Shifts and the Role of Education}

If in education we have treated digital technology as a simple enhancement to learning, but have largely ignored its implications for equality, diversity and inclusion policy, the same could be said of the omission of critical, emancipatory educational theory from development of new artificial intelligences. Now though is a pressing time to examine ethical tensions, bias and discrimination that can occur at various stages in computing design, development and application, and what this means for inclusivity policy. We are living with real impacts and inequalities in people lives that have emerged through disciplinary divides between digital computing, the humanities and social sciences. Many studies in human computer interaction (HCI) are now examining the intersections across disciplines that might better inform more ethical computing design and algorithmic activity. There are postdigital complexities too that 
encompass more than simply design. Very broadly, there has been a developing need for us to reconnect cultural and technological developments (Delanty, 2001: 157) through education. This is becoming more apparent, as recent global green agendas pin hopes for sustainable futures on bioeconomic developments based on biodigital technologies, but also place education as central to the global Sustainable Development Goals (SDGs) being achieved (UNESco, 2020d).

Now that an evolutionary shift presents itself in the form of biodigitalism, our natural and cultural environment is converging with digital advances. This brings new ways to reduce our emissions and develop renewable energy and resources (Peters, Jandrić \& Hayes, 2021b). Fundamental changes to how humans perceive themselves and their roles will follow. The concept of being postdigital offers a productive (but not perfect) route that enables human subjectivities, rather than objective rationalities alone, to be explored in this context:

The postdigital is hard to define; messy; unpredictable; digital and analog; technological and non-technological; biological and informational. The postdigital is both a rupture in our existing theories and their continuation. (Jandrić, Knox, Besley, Ryberg, Suoranta \& Hayes, 2018: 895)

The Springer journal Postdigital Science and Education was formed in 2018 for exploratory and inclusive purposes. It has enabled the adaptable concept of being postdigital to be shaped, extended and applied in multiple situations to reveal subjective and collective experiences. Just as McDonaldisation has been adapted to be explored in different contexts to demonstrate all manner of large-scale global rationalisation based on production and consumption, the postdigital can be owned and varied positionalities on it shared. I chose the title of postdigital positionality to enable counter arguments to neoliberal rationalities and generalisations about inclusive practices, as these play out in McPolicy across HE. There will be opinions too on whether linking the postdigital perspective with positionality theory does shed any light on new ways into inclusivity policy in universities. It provides a talking point though, that aims to be inclusive in inviting those opinions.

\subsection{Postdigital Positionality Avoids Digital Bureaucratisation of Meaning}

Therefore, postdigital positionality is a concept under development, and rather like a beta phase of testing in computing, there could be some known or unknown bugs for readers to find. In the process we may arrive at something better, but for now it gives us something to work with and refine. Computing 
techniques are applied in all manner of human activities across organisations, along with objective goals that seek greater quantitative efficiency. Insights from the humanities applied to better understand computing and data activities instead lean towards a more qualitative, subjective analysis. Currently inclusion policies and rational digital skills agendas are overlooking many ethical implications that emerge from such analysis. There should not be separate agendas that pick and choose some issues of student or staff wellbeing and not others because humans have never been more subject to rational forms of computer processing with related impacts on their emotions and health.

The Covid-19 pandemic, and the need for humans to distance from each other and work online, has also added numerous biological and informational complexities to the postdigital contexts that humans now occupy (Jandrić, Knox, Besley, Ryberg, Suoranta \& Hayes, 2018). Massimo Leone (2020) has explored the issue that 'insignificance' is seeping into our everyday lives. He suggests that the progressive digitalisation of our very ways of being 'is turning the relation between subjects and objects, as well as that among individuals, into empty stereotypes' (Leone, 2020: 1). This is leading to contemporary 'obsessions' and therefore we require 'strategies to resist the alienating effects of the digital bureaucratisation of meaning' (Leone, 2020:1). Material and digital reactions to this situation can be observed, from a desire to personally make a mark of some kind, such as tattooing the body, placing placards in windows during lockdown, taking part in a physical demonstration, trolling others or oversharing, across an online forum.

Additionally, a 'therapeutic' ethos that has diffused across society and into education, points to further examples of a human need to be noticed, such as 'presenteeism' (Ecclestone \& Hayes, 2019: 108), as does a desire to be 'memorable' as a person, in the form of a 'selfie' (Leone, 2018: 44). There are others who attach padlocks to bridges to signify their presence and regard for a lover in the form of 'love locks' (Hayes, 2019: xi), as shown in Figure 9, where a stray face mask has been included. Further individual forms of expression have taken the form of protests against the enforcement of facemasks, lockdowns and general infringements of liberty.

Ultimately, whether we know it or not, we are now in a zone of being human where we need to choose whether we become postdigital objects alone or learn who we might become also as postdigital subjects, each with our own unique positioning. Postdigital positionality recognises human autonomy within each of our individual contexts. This subjective stance places each of us in a stronger position for emancipatory forms of collaboration in education where individual diversity is recognised as a strength over rational objective statements of excellence that render each of us as insignificant. 


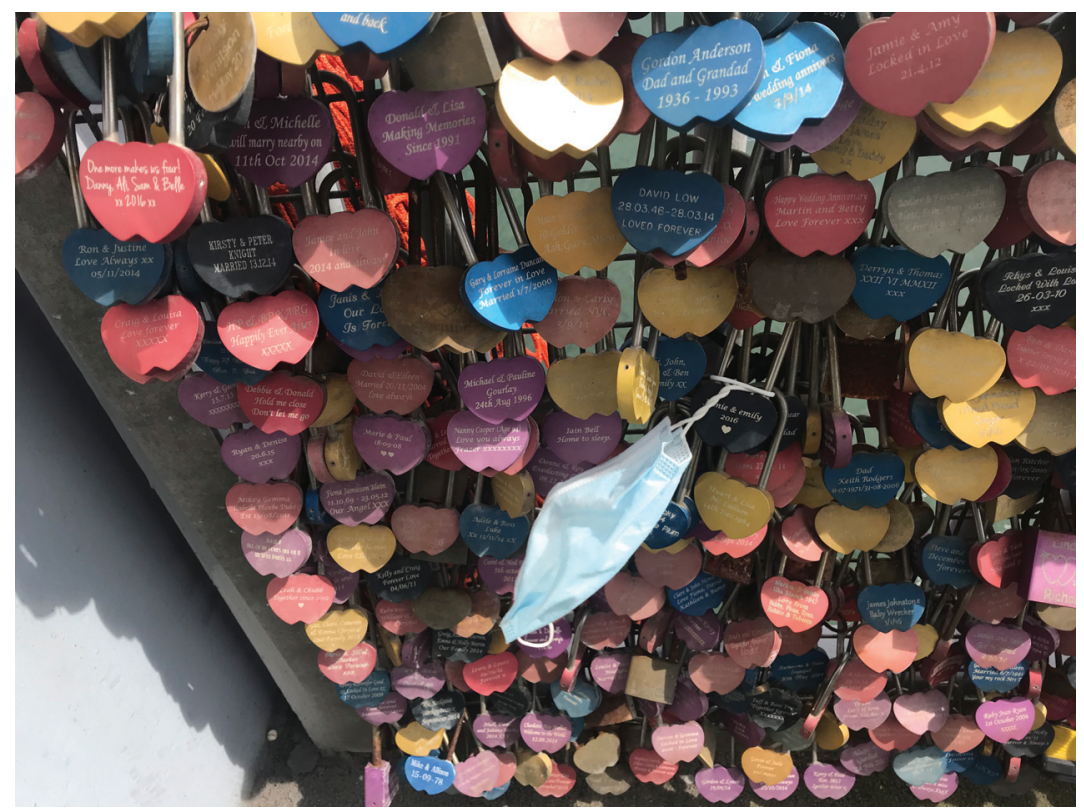

FIGURE 9 Love locks on a bridge are joined by a face mask

A lot of rational computer processing and data collection taking place around us currently goes unnoticed. Some authors have suggested that the term postdigital refers to just this. Thus, the Internet and digital capacity, just like electricity, will only be noticed now through its absence, or when things go wrong (Negroponte, 1998, Cramer, 2015, Jandrić et al., 2018). This in itself though is still only part of the picture, when there are still many people globally and locally who are not able to access digital services for many different reasons (Traxler, Smith, Scott \& Hayes, 2020). Yet, a lack of personal access to digital activity does not necessarily exclude people from other forms of physical surveillance, having data collected about them, or others discussing them during online conversations and sharing their images across social media. Whilst this book focuses on the context of inclusivity, in relation to HE policy, many of the ideas that are explored are applicable to all of us, in whatever location around the globe. The pandemic has forced new human dependencies on digital means of communication, online working, virtual health and social services appointments and has also drawn attention to disparities of many kinds.

\subsection{Unconscious Bias from Humans Encounters Conscious Bias from Machines}

Problems with the divide between policies that aim to address equality, diversity and inclusion, and those that discuss technology as a separate driver of 
change to rationally support market-driven economic aims, can be noticed with regard to the treatment of bias. Returning briefly to the analogy of the airing cupboard, it is easier to respond with a bias towards what is spilling out at the front, when I open the door. This means little attention is paid to the items closer to the pipes and the hot water tank further back, well at least until something goes wrong with this technology. In the virtual airing cupboard of online opinion, the devices and technological platforms through which so many comments are expressed are given little consideration, as they operate in the background. They gather and distribute data through computer programming that reflects their purpose, but also generate and contribute to bias, alongside humans. All manner of preconceptions, presumptions, partiality or prejudice can be at work out of sight due to opaque operations that users are largely unaware of. The present focus remains on human bias of the type involved when humans express opinions in the moment (or act accordingly), that are quickly cancelled by others. This demonstrates the disconnect between 'cultural reproduction and technological reproduction' (Delanty, 2001: 157). A postdigital perspective is one route towards connecting the two. Whilst individuals are 'cancelling' each other online over different isolated gestures and comments, there are deep and multifaceted inequities that play out across institutions, structures and the programming of technologies. Online or offline, 'battles of cultural identity' (Delanty, 2001: 157) are both cultural and technological, in terms of bias.

As an illustration, for some time now many organisations and companies have required their staff to undertake unconscious bias training. This is said to address issues of implicit bias, sometimes discussed as prejudice, or unsubstantiated judgments either supporting, or discriminating against one thing, person or group in comparison with others, in ways that might be deemed unfair. Amidst a recent row where some UK Members of Parliament (MPs) who were urged to undertake unconscious bias training, instead rejected it (Murphy \& Walker, 2020), some people argued that the training might be viewed by employees 'as something which should enable them to better do their job'. Others commented over Twitter that such training is 'patronising' and that a form of 'snowflake' training should be offered to the providers of unconscious bias training themselves, in retaliation. There were comments too that suggested that by refusing to do this training, the MPs 'say something unpleasant about themselves' (Whitaker, 2020).

There are others who air alternative perspectives on this topic, arguing that (rather than cancel each other) people and organisations should cancel the unconscious bias training itself. They point out that organisations are simply 'rushing to tick the box of unconscious bias training' in response to recent 'civil 
unrest over systemic racism' (Liesch, 2020). This is based firstly, on a claim that unconscious bias training was not actually created as a solution for systemic bias, prejudice and discrimination. Instead it was 'designed as a risk-mitigation and compliance tool. Furthermore, 'it was not designed by people who experienced and understood discrimination, but by corporate lawyers who were intent on protecting their organisations from litigation' (Liesch, 2020). Whilst this comment on design may be so, a key argument for holding open debate about postdigital positionality as a concept, is to avoid assumptions of what others may or may not have 'experienced'. In the virtual airing cupboard, there is a great deal of voicing of what others are expected to 'feel', perhaps connected too with a widespread preoccupation with emotional difficulties and popular therapy (Ecclestone \& Hayes, 2019: 5).

Further issues raised concerning the training itself, are that many features that could help to foster 'less biased, more equitable, and lasting behaviour change' have not been included. For example, 'voluntary participation, a focus on the system as opposed to the individual and practising equitable behaviour over time'. Instead, training is 'mandatory, targeted at the individual and conceptually disconnected from day-to-day work' (Liesch, 2020). There are also numerous ways in which cognitive bias affects each of our actions.

We cannot count the number of ways that dimensions of identity intersect in a given person at a given point in time. The world is waking up to the fact that we cannot train the bias out of anyone. (Liesch, 2020)

Wherever readers of this book choose to position themselves on the topic of unconscious bias training, there is a discussion to be had about not only the design approach for staff sessions but also the design and potential ingrained bias of technological platforms that deliver such training. Furthermore, the arguments expressed by Liesch (2020) are made from a position with a commercial interest, appearing on the Tidal Equality website, which seeks people to trial their alternative form of training, called Equity Sequence. This illustrates the varied and vested interests that positionality theory can help reveal. Thus, exploring the postdigital positionalities of individuals calls into question the objectivity or neutrality of any actor (human or not), effectively arguing that usually someone's interests are at stake. How that 'someone' is now perceived in a postdigital context requires new thinking in relation to inclusivity policies. To write these without full acknowledgement of the role that technological change now plays in people's lives and in universities, could be said to be an act of exclusion in itself. 
This is because, firstly, the numerous facets of people's identities are no longer constructed via human and social means alone. We are all now (whether we ourselves use technology, or not) partly constituted through data created by us, or about us. Data-driven systems are a part of all of our lives, monitoring, evaluating and reconstituting different aspects of human existence. Whilst some of this activity is more recognisable than other aspects, we are now partially formed by the mobile, communicative, wearable, implantable, programmable, transportable, connectable, invasive and disposable devices and data, that organise and co-construct how individuals perceive daily life. Thus, the positionality of individual humans, which was traditionally discussed by qualitative researchers to explain how their ontological or epistemological values may have influenced a project outcome, is worth extending. The lens of positionality offers one way to examine the web of complexities humans and technologies bring to inclusive policy and practices.

Secondly, I suggest that the positionality of non-human actors (in terms of their political context, potential bias, origins, development, ethics, accessibility, legibility, negotiability and accountability) increasingly need to be taken into account, alongside discussions about the positioning of humans. These are not merely interesting questions, they also have deep ramifications for inclusivity in education and across wider society, if they are overlooked.

Therefore, in the rest of this chapter, following further examples that illustrate the first point, I will then describe how positionality has been understood more traditionally in a research context. I will explain why exploring positionality in a postdigital context offers new insights for HE inclusivity agendas and I will discuss some examples of postdigital positionality during the pandemic. It is important not to view these instances in isolation from what might be learned for future directions in $\mathrm{HE}$. In terms of the second point, I will share technological examples that illustrate ramifications for positionality and inclusivity in education and across wider society, to show why inclusivity policy discourse would benefit from a reboot.

\subsection{Living with Technology and Diversity as Fluid Not Static}

New arrangements now define human relationships in society, given that intelligent computer systems and algorithms are daily residents in many of our lives (Jandrić, Knox, Macleod \& Sinclair, 2017). This though requires a different way of 'thinking of technology which does not decide upon its status in advance' (Dawson, 2019:463). The same could be said of diversity. Simply stating words like technology or diversity in policy as if these were simple solutions (like unconscious bias training), misses out on the fluidity of lived experience. In 
her book On Being Included, Sara Ahmed (2012) discusses diversity as an ordinary, even unremarkable, feature of institutional life, but one that manifests as multiple embodied realities. So it is with embodied experiences of technology, as these intermingle with fluid experiences of diversity. Ahmed emphasises a need to ask what diversity does and what we are actually doing when we use the language of diversity. To ask the same questions about technology and data (as part of the conversations on diversity and inclusion) would be a powerful connection.

The problem in HE policy is that we have, for some years now, ascribed a status to words and buzz phrases that has hidden from sight the related facets of human labour, technology and relations with diverse individual subjectivities (Mautner, 2005). Static forms of policy discourse have shaped the identity of students as a faceless 'body' via statements like 'the student experience' (Hayes \& Jandrić, 2018). This phrase linguistically conceals the diverse routes that students take through $\mathrm{HE}$, including how each person may experience successes, challenges and inclusion in unique ways, depending on their positionality.

As individuals and institutions, an array of online and social media identities, as well as data-driven computing devices now participate with us (and for us), both in, and outside of, academia. Technologies harvest and curate both products and people who might interest us, based on close surveillance of our online actions on Amazon, LinkedIn, Facebook and many other platforms. Yet, in many local and global contexts these interactions vary too, in terms of who has access to digital ways of living and learning and how these are enacted culturally (Traxler, Smith, Scott \& Hayes, 2020). Then there are others in society who by choice still seek to avoid digital technology, where possible. Examining social theory concerning technology, oppressive and liberating forms of power, politics and language surrounding education and individual positionality through a postdigital lens, can address our current environment of rapid socio-technical change. This includes attention to what existed before digital and what may exist beyond:

Instead of assuming as a starting point a dichotomy between analog and digital educational forms of life, it assumes that they are always already plugged into one another: a flesh electric. (Lewis, 2020: 265)

This colourful idea also helps to avoid a situation where policy discourse is critically analysed in isolation from cultural and technological context. Plugging these into one another as a 'flesh electric' would power up the inclusivity policies with dynamic enactments of diversity and technology. Our policies need a recharge, and a regular installation of updates. 
So, whilst some research studies challenge hegemonic policy language, and others address a flow of platform capitalism into $\mathrm{HE}$, few draw out perspectives on the fluidity of technology and diversity in individual lives and what this means for institutional inclusivity policies. How this fluidity plays out in each of our postdigital, academic lives requires a reflexive appreciation of these connections and possibilities. Tyson E Lewis has summarised where such discussions might lead, if only we had the courage to 'ask a vampire squid' for some sound advice on moving forward:

To invent new kinds of postdigital, diabolical fables that enable us to acknowledge the other in ourselves and ourselves in others across any purported digital or species divide in such a way that the uncanny space of mirroring produces joyous encounters rather than merely destructive ones. (Lewis, 2020: 266)

\subsection{Postdigital Spaces Where Human Identity Is Enacted}

The key thesis put forward in this book is that people each have a 'postdigital positionality' that has a 'dialectic relationship' (Freire, 2000: 50) with other key elements of their individual identity and experience. This is because there are new postdigital spaces in which human identity is now enacted, reduced, evaluated, challenged, threatened, empowered or reconceived. Thus, I suggest that developing postdigital positionality theory offers a fruitful route towards stronger individual and collective agency and narratives in $\mathrm{HE}$, where it is fully acknowledged that humans are inextricably intertwined with both digital and predigital technologies. This means that a person's beliefs, political stance, cultural context, location, gender, race, class, socioeconomic status and educational background are all variables and experiences that are not only framed in socio-cultural circumstances, but now in complex socio-technical ones too. As such, they have a postdigital positionality that is unique to them.

Once such a debate is explored, this provides a powerful argument against empty policy or media rhetoric that mindlessly imposes broad categorisations on human beings, that they may not choose for themselves. There is space too, for people to change how they perceive themselves and their positioning within an ever-changing postdigital context. This is important when the placing of people into any kind of grouping risks objectifying human qualities, which can swiftly turn into linguistic constructions that attribute actions to this group, or even state (on their behalf) how they should live or what they should feel. If 'within positionality theory, it is acknowledged that people have multiple overlapping identities' (Kezar, 2002: 96), then postdigital positionality theory is inclusive of how both the digital and analogue now merge with 
many other aspects of personal identity to develop a person's positionality. As Crenshaw (1989) has pointed out, identity-based politics has enabling aspects for people of different gender, race or those with a disability, but it can also cause individuals to become labelled within one group, when they may identify with other groups in society too. In the case of violence against women there are intersections between, for example, race, gender, and politics, but there may also be points where these cross-cutting experiences further intersect with disability, or mental illness. However, as human cases are increasingly discussed online in the news and via social media, or classified in a database, or the person involved feels excluded from parts of life, their identity is also being shaped by these digital platforms.

\subsection{When Does Human Identity Become Data, or Data Become Identity?}

Exploring one's own postdigital positionality offers an insight into the recognition of broader factors that may be contributing to potential isolation, self-worth or discrimination. There are examples to be noticed in the apps we choose ourselves, but we may not be aware of (or even care about) the data these gather on us. Yet, an app intended to raise confidence, or help with weight loss, or wearable exercise devices, are not just simple tools or additions to people's lifestyles. The ways in which they have been programmed, marketed and how they operate with an individual's perceived identity, helps to demonstrate how what is digital, is closely associated with what is not, and both become blurred as data is collected and used.

Then there is the question of surveillance technologies such as facial recognition that gather data in public spaces. Recent backlash on these controversial technologies has now resulted in some US cities banning their use, citing 'the risk of biases against Black people, women and older people' (Hatmaker, $202 \mathrm{ob})$. Such decisions are significant in terms of data privacy, given that some facial recognition software even 'allows clients to upload a photo of anyone to cross reference it against a massive database full of photos scraped from online sources, including social networks' (Hatmaker, 2020a). In a recent landmark case in the UK, the use of AFR Locate was argued to have breached human rights when biometric data was analysed without the knowledge or consent of the individual concerned. The court upheld that there was 'no clear guidance on where AFR Locate could be used and who could be put on a watchlist, a data protection impact assessment was deficient and the force did not take reasonable steps to find out if the software had a racial or gender bias' (Rees, 2020).

Yet, in a somewhat irrational twist, Covid-19 has now led to the demand for an increase in tracking and surveillance. This includes 'webcams to enable customers to check online to see how busy the high streets are, in a bid 
to help with social distancing' (Beardmore, 2020). Track-and-trace apps have been enlisted despite concern over invasion of privacy (Amnesty International, 2020). Alongside humans adapting to working online more autonomously, 'tattleware' software, such as Interguard and Sneek are being bought by companies to increase surveillance on their employees, taking photos of workers as often as once a minute (Gabrielle, 2020). Such examples help to show how data privacy takes on a life of its own across platforms, demonstrating a multidirectional flow of how human identity might be appropriated into data, and in turn, human data (such as photos or bioinformation) might be sold or used in potentially discriminatory ways. Developments in neuroscience and neurotechnology have been analysed in relation to human rights to identify:

Four new rights that may become of great relevance in the coming decades: the right to cognitive liberty, the right to mental privacy, the right to mental integrity, and the right to psychological continuity. (Ienca \& Andorno, 2017)

It therefore becomes important for universities to avoid inclusivity policies that home in specifically on issues related to the human body but that overlook issues related to the mind, or vice versa:

While the body can easily be subject to domination and control by others, our mind, along with our thoughts, beliefs and convictions, are to a large extent beyond external constraint. Yet, with advances in neural engineering, brain imaging and pervasive neurotechnology, the mind might no longer be such an unassailable fortress. (Ienca \& Andorno, 2017)

Many social media platforms are now routinely used by people 'to raise awareness 'for the racial, civic, and social causes they care about' (Dickey, 2020). This has led to Instagram 'building a product equity team and hiring a director of diversity and inclusion' and thereby taking responsibility for what they build into their system (Dickey, 2020). In the context of marketised education, the use of many commercial platforms sits alongside aspirations for inclusive practices. Is there not a need now for universities to bring in their own response to product equity scrutiny? This would be a small step towards acknowledging that technologies carry more than just a perceived efficiency into universities. They have earned their right to be scrutinised by inclusivity committees along with the data they gather, because the use of such commercial platforms has wide reaching implications beyond enhanced efficiency. 


\subsection{Were You Abused by a Human or a Computer Program?}

Just when it seemed as if the questions that humans were grappling with concerning 'political correctness' (Lea, 2010) were complex enough, examples of algorithmic activity, such as 'keep calm and rape t-shirts' were autogenerated by a 'scripted computer process' (McVeigh, 2013). A more recent study from the United Nations Educational, Scientific and Cultural Organisation (UNESCO) highlighted the way in which AI generated female voices can also generate bias in companies such as Apple and Amazon. The report questions 'the male engineering teams who have built AI systems that cause their feminised digital assistants to greet verbal abuse with catch-me-if-you-can flirtation' which can send a signal that women are docile helpers with no agency, available at the touch of a button to honour commands regardless of their tone or hostility. 'In many communities, this reinforces commonly held gender biases that women are subservient and tolerant of poor treatment' (West, Kraut \& Ei Chew, 2019). Without sounding too facetious, such programming issues could be heading into a university or college near you, ready to quietly reinforce inequalities that inclusivity policies have been seeking to address.

A lot written about academia in recent years is of a cautionary nature, with many articles describing academic oppression, anxiety and despair (Gill, 2010, Hall \& Bowles, 2016, Hall, 2018). These papers reflect personal stories of pain felt by those on short-term, precarious contracts, victims of bullying, inequalities, mental health issues and overwork. Where once rational lines of bureaucracy, and indeed academic autonomy, were more obvious to spot, it is now harder to tell where many rules, instructions, data and judgements are actually coming from, or going to. It has also become trickier to distinguish between the acts of humans and those of computer code, between government and media interest in universities and strategic institutional or political decision making. This raises questions about the role of fake news in a post truth era (Flood, 2016). On a personal and institutional level, there are emerging issues concerning trust, disillusionment, ethics, reliability and bias, bringing complexity and obscurity into education, welfare and health.

Hearing from individuals in their own voices about their positionality in $\mathrm{HE}$ is helpful in distinguishing what might be seen as authentic knowledge in an era of fake news. Questions can be asked about who the 'knower' is and from what position they are speaking, writing or gathering data. There are links here to human trust, emotions and generosity, when kindness is a seriously under-rated virtue in a marketised higher education sector' (Welch, 2020). This has implications for new critically reflexive understandings of leadership and policymaking, as well as for learning, teaching and research. For example, if an author seeks to examine how either racial or gendered identities might inform leadership 
development and challenge hegemonic discourses, it is now expedient to also consider the postdigital context in which these discourses are constructed and distributed, as well as deconstructed or reconfigured. Therefore, postdigital positionality ought to be personal, collective and inclusive of all, because everyone can contribute to what this means as lived experience in their context.

\subsection{Civic Dimensions to Postdigital Academic Lives}

Human and computer systems are interwoven with neoliberal forms of organisation in universities and colleges. Yet they fuse seamlessly too, with opinions given all too generously, on social platforms, in the virtual airing cupboard. They fuse too, as pre-digital elements of society and civic life. This means that our status as individual hybrid, postdigital beings brings implications for learning, research, university strategy and work in wider civil society, even as we experience globally and locally emerging effects of a Fourth Industrial Revolution (Schwab, 2017, Peters, Jandrić \& Hayes, 2018, WEF, 2019, Connor, Mahoney \& Lewis, 2019, Hayes, 2019c). Nurturing a vision beyond formal courses, clear connections to civic education that values democratic voices and recognises regional and global changes is important. The pandemic has augmented many fundamental changes that were already happening in terms of automation, with implications for all citizens. For example, there are signs that the Covid-19 crisis has speeded up the process of robots replacing humans. This gives rise to questions on where matters of identity, diversity and value for humans and technologies will sit in the coming years. If some predictions are correct, then we could see humans settling into the back seats in academia (just as they might do in a self-driving car):

People usually say they want a human element to their interactions but Covid-19 has changed that, says Martin Ford, a futurist who has written about the ways robots will be integrated into the economy in the coming decades. (Thomas, 2020)

From robot cleaners for institutions and offices, to fast-food chains like McDonald's testing robots as cooks and servers, Covid-19 has accelerated a shift away from humans and toward machines. Aspects of this automation are warmly welcomed to keep critical services running and spare us from disease (Thomas, 2020). There are also aspects of human loneliness being met by 'Chatbot girlfriends' and other practices of seeking romance or friendship from artificial intelligence (AI), thus removing human partnerships and replacing these with computing alternatives (Olson, 2020). There are changes to transport as autonomous means of delivery receive a boost helping 'customers reduce physical 
contact and address labour shortages caused by lingering quarantines and travel restrictions' (Bloomberg News, 2020).

Universities are not immune to these commercial changes and consumer preferences induced by self-isolation and $4 \mathrm{IR}$, now working in tandem. A march of digital platforms into $\mathrm{HE}$ to cater for online interactions during lockdown has been followed by the usual 'migration' of students back onto university campuses during the autumn of 2020. Their return has received more interest than usual though, with diverse online commentary on the risks that students may pose to the citizens in the cities they are travelling to in order to study (в BC, 2020с).

As automation competes with the need for human activity there are also curious postdigital examples where pre-digital scenes have returned that might have been thought unlikely just a year ago. The notion of milk floats and milk men and women returning to deliver milk to homes might have been considered as being 'consigned to the history books by the rise of the supermarkets'. However, 'thanks to the coronavirus pandemic, these dairy deliverers on their electric floats are busier than ever as they try to keep up with newfound demand for their services' as 'shoppers try to reduce, or forgo, their trips to supermarkets' (Parveen, 2020). Then again who would have imagined that drive-in movies would have found a renaissance either, as New York attempted to provide 'family-friendly, socially distant fun' (Rein, 2020).

Examples then that provoke a glance backwards, as well as forwards, when contemplating the future of life, learning and what constitutes inclusive practices beyond the pandemic. With this in mind, although it is necessary to expose the problems of our current state, it is worth considering what other reactions, besides panic, may be open to us in this context:

At moments of radical social and cultural change such as literary studies is experiencing now, we need not panic. We need to avoid the pessimistic and dystopian thinking that dominates much of the contemporary popular literature on the supposedly detrimental impact on attention and education of digital media and technology, and avoid the technological determinism which accompanies such thinking, as if digital media and technology might have some inherent traits and affordances that exist before or beyond their use by the user, reducing us to mere actors without agency, let alone hope - but an intra-active posthuman agency is much more powerful than that. (Ablitt, 2019: 105)

Writing with reference to a postdigital paradigm in literary studies, Ablitt argues above that there is no crisis, because the postdigital 'doesn't negate but instead enhances that which came before' (Ablitt, 2019: 105). 
Many publications and conferences now call for radical change away from marketised universities and colleges where learning and learners themselves, are commodified. Some suggest that a new 'vision' is required to 'shift the way education workers, students and the general public think about the politics of education' (Gamsu \& Hall, 2019: 83). Others point to the profoundly political nature of adult education that historically has enabled access for those who would otherwise have been excluded, calling for broader conceptions of civic education envisioned by the 1919 government Report on Adult Education (Clancy, 2019) and the Adult Education 100 Campaign (WEA, 2019).

Certainly, as people have become displaced from workplaces of all kinds, there is a need for inclusivity in $\mathrm{HE}$ to operate in the broadest possible sense. Therefore, dialogue concerning the postdigital context surrounding those of us in HE needs to connect with overlapping civic concerns in the regions surrounding institutions. Postdigital positionality requires a broader approach than university regulatory bodies have been used to so far. Therefore, agencies such as the Office for Students in the UK and similar quality control bodies elsewhere can no longer treat 'data' as isolated from the interconnected cultural and technological spheres of civic life.

\subsection{Filling the Void of Excellence with Data}

$\mathrm{HE}$ now has multiple regulatory frameworks for excellence, yet as Readings pointed out in 1996, 'today, all departments of the University can be urged to strive for excellence, since the general applicability of the notion is in direct relation to its emptiness' (Readings, 1996: 23). A quarter of a century later, we now seek to fill this emptiness with data. Data-driven university access and participation policies make reference to fairness, morality and transparency, as they seek to address concerns over progression and attainment gaps for different social groups and ethnicities (Office for Students, 2018). However, such concerns are now also part of a much larger picture that can no longer be overlooked. Those writing university policy based on 'human' values, now need to consider how these are also infused by Artificial Intelligence (AI) algorithms, whose reasoning on exam results, recruitment, actions and ethics act both digitally and physically in people's lives (Hemment, Belle, Aylett, Murray-Rust, Pschetz \& Broz, 2019). This new hybrid context includes concerns about the 'platform university' (Means, 2018, Williamson, 2019b) and effects on how students and staff are 'positioned', and on how they come to view this positioning, in relation to their aspirations in or for education.

Fawns Aitken and Jones (2020) have raised concerns about a datafication of 'teaching quality' that now takes place, where digital traces of educational activity are increasingly generated, harvested, analysed, and mobilised in ways that foreground instrumental understandings, not only of evaluation but of 
education itself (Fawns, Aitken \& Jones, 2020). As such, they argue that valuation must take account of those aspects of teaching, learning, and educational context that are missing from digital data. They are not alone in arguing against the measurement of teaching quality through selective data.

In a Special Issue entitled 'Measuring Excellence' in Higher Education (Hayes et al., 2021), a group of authors explore the concept of 'measuring excellence' and 'the dilemmas it raises in the postdigital context now surrounding universities, including the complexities thrown into the mix by Covid-19' (Hayes, 2021). Postdigital positionality is one way to uncover and to better understand these complex and often hidden aspects of academia. It offers a route for exploring how facets of our identities as teachers, researchers and leaders are also infused with digital, pre-digital and post-digital elements. A postdigital debate can help draw attention as to why educational activity cannot simply be 'skewed towards generating favourable data' where outcome measures concerning grades and retention alone are 'taken as isolated proxies for quality' (Fawns, Aitken \& Jones, 2020).

Such entanglements with data-driven technological and human systems have diminished the levels of control that humans can exercise over their own situations. This has links too, with a 'wider therapeutic turn in popular culture, politics, personal and institutional life' (Ecclestone \& Hayes, 2019: ix).

These aspects of postdigital life manifest themselves within universities in the form of wellbeing agendas, counselling, moves to combat loneliness, policies to increase a sense of belonging and in the physical shape of safe spaces and therapy animals to reduce anxiety. According to Berg, Huijbens and Larsen (2016), 'a rise in anxiety must be seen, in part at least, as the result of the neoliberalisation of the university'. Yet, when digital change and automation have ridden in tandem with the political economic changes wrought by neoliberal forms of capitalism, these aspects of societal change need to be examined together. Whether societal progress is based on physical tools or virtual instruments, human labour and values remain a constant amid technical and cultural change (Hayes, 2019a: 147). The difference now, is that human choices are becoming indistinguishable from those taken by machines that act as proxies for humans. We are therefore at a crossroads where we each need to choose our positionality, before this is decided for us.

\section{$2 \quad$ Positionality in a Traditional Sense}

Positionality has a dual meaning traditionally where it refers firstly, to the social and political context that creates a person's identity, in terms of, for example, 
their gender, race, class, location and ability. Secondly positionality involves how a person's identity influences, and also potentially may bias their understanding and outlook on the world. Such discussions have been conventionally important in relation to researchers and the research process (in particular for qualitative researchers, although I argue that postdigital positionality now has an increasing importance for people universally) in explaining their part or influence in any research or indeed other activities that they have undertaken. This dual meaning of positionality is core to the topic of this book and to the twofold debate discussed at the end of the introduction. Firstly, that it is necessary to acknowledge a new postdigital context in $\mathrm{HE}$ where multiple and diverse 'actors' (that are not all human) are now altering much of what may once have been described as 'established' or 'inclusive' practices in universities. Secondly, exploring what this means across all of the key activities of $\mathrm{HE}$ is necessary in order to notice how educational access, inclusivity and opportunities for any individual person may now be altered in complex ways, depending on their 'positionality'. So, I will provide an overview of how positionality has traditionally been understood, in relation to the role of a researcher in connection to their research methodology and outcomes. I will then bring this into the twofold debate this book raises to help to explain a relevance for all of us.

Part of each research study habitually involves explaining how a researcher or a research team's 'position', as they understand it in terms of their human identity and context, has implications for the research choices that they have made. Position is inclusive of many considerations, such as a person's location, their status, gender, ethnicity and their point of view, values and opinions. The researcher themselves must reflexively interpret which aspects of 'who they are' should be disclosed and explained in relation to their research focus and its outcomes. As an example, if you are a white researcher seeking to understand how students of diverse ethnicities may be experiencing aspects of university, then it is important to be cognisant of one's own positionality: as a white person in a particular setting, drawing conclusions on the experiences of others, whose ethnicity is different from your own (Bourke, 2014). To genuinely acknowledge the assumptions that could be influencing the research choices made in this situation, is to appreciate that undertaking research to better understand something about others, is a messy business. Any illusions of objectivity need to be challenged because research is an 'ongoing dialogue with different social worlds' (Holliday, 2016: 7).

2.1

\section{Tenets of Positionality in Postdigital Society}

On this note, Torres-Olave and Lee (2019) suggest that positionality is constructed around three main tenets: (1) identities are complex and fluid, (2) they 
are enmeshed in power relations and (3) they are contextually bound. As well as recognising the importance of intersectional factors such as race, ethnicity, class, gender, age, nationality and sexuality in shaping human experience, they argue that other areas such as what positionality means for scholars whose work (and lives) crosses different national boundaries are under researched. They point also to the need for a reflexivity that goes beyond the mere acknowledgment of social identity as static and towards a need for a better accounting for people's dynamic situational context. Included in this is the worldliness, or fleshliness of experience, and the dynamic role that time and space play (TorresOlave \& Lee, 2019). I would argue then that how these three tenets, around which human positionality is said to be constructed now intersect too with people's postdigital situational contexts, is particularly relevant for inclusivity agendas. They cannot ignore the 'flesh electric' (Lewis, 2020: 265) aspects of people's lives. It is not only researchers who find themselves in 'ongoing dialogue with different social worlds' (Holliday, 2016: 7), this is something that affects us all. In other words, there are countless subjective variables at play in such dialogues, in terms of individual positionality, as this now plays out across postdigital society.

The arguments put forward by Torres-Olave and Lee (2019:4) are made in the particular context of research in international locations, where they point out why researchers themselves cannot be treated as 'disembodied' from what is being studied. They explain why researcher identities cannot be presented as 'impervious to change and neatly telegraphed in the requisite methods section, not to be re-examined again in the remainder of the text' (Torres-Olave \& Lee, 2019: 4). The shifting nature of human subjectivity, as this then moves into a different place and time zone, is said to also bring with it, certain effects. The physical bodies of those of us engaging in research abroad 'may be in a very different "space" than our minds, including our beliefs and assumptions' and what is 'marginalised in one country or region may be marginalised differently in others, or not at all' (Torres-Olave \& Lee, 2019: 4, Traxler, Smith, Scott \& Hayes, 2020).

As someone who has taught and undertaken research in different parts of the world (including such varied locations as: Italy, Vietnam, Ghana, Singapore, Muscat, Australia, Greece and Denmark) this is a lived experience that I can echo. The very nature of travelling to another nation, eating different food, participating in local cultural activities and talking with local people there, alters my perspective. As a white female teaching in some locations it has been necessary for me to dress differently, to show respect in particular ways that are accepted in that region for certain beliefs, values, items or physical places. As a sociologist, educator and researcher, I have found that being physically present in a different country to teach also changes how I write a research paper. 
It is possible to plan teaching and research activities in detail before travelling somewhere, but it is then a process of flexible adaptation as I internalise both the unfamiliar context and the ideas that my hosts and participants share:

We were given a formal introduction to the Assistant Director, Internationalising HE (India), who facilitates internationalisation activities on behalf of the British Council in India and to our hosts and details of the programme our workshop would be delivered within. Day 1 would be a conference, where government officials would lay out expectations, and a local e-learning expert would be present. In Vietnam, we participated in a local quality conference, which followed our taught programme. In Hyderabad, we could absorb the unfamiliar context on Day 1, tweak our approach to support local aspirations and notice cultural nuances not visible through email. (Lamb, Bartholomew \& Hayes, 2017: 214)

Here I am describing my own processes of adjusting to undertaking several days of teaching in locations in India (2016) and in Vietnam (2015). Whilst this brief account gives some insight into these formal contexts and preparations, the teaching rooms, facilities, access to Internet and living accommodation where I stayed were completely different. Expectations, customs, attire and political contexts were also diverse:

After anticipating as much as possible, there is a need for an ongoing reflexivity within a UK teaching team abroad to integrate local, culturally important aspects and political agendas that it would be hard to be aware of before teaching in the host institution begins. (Lamb, Bartholomew \& Hayes, 2017: 216)

Whilst Torres-Olave and Lee (2019) were discussing positionality in research, many researchers are also teachers. Paying attention to identity, location and power relations in terms of our own positionality and that of others helps to avoid a rational, disembodied or instrumental approach towards the complexities of inclusivity.

\subsection{Positionality Goes Public, Global and Viral}

What I didn't share in the excerpts above, is the personal emotion that I carried with me as I prepared to teach in India in 2016. I was missing the funeral of a close family member back in the UK who passed away just days before I was due to fly. There are some decisions that researchers have to make in terms of just how personal a statement of positionality they will record in relation to 
the study they have undertaken. This will depend too on the topic and how intimately involved they are with it, their choices they made in their collection and analysis of data, as well as how this is eventually summarised as results for publication.

This is interesting to reflect on when digital platforms have now enabled extensive sharing of intimate personal details to global audiences. There are many news websites where, alongside breaking news tragedies, personal narratives and experiences of every aspect of life's minutiae are featured. These are specific, personal positionality accounts that have gone public. They place an individual's circumstances, plight, decisions, dilemmas, appearance, happiness, achievements or experiences of discrimination, injustice or pain onto the phone screens of others who are clicking their way through the news. Those who read these details are forming opinions wherever they are located and linked to their own values. Therefore, how certain technologies and indeed social and cultural movements and related data are disseminated is having a cumulative effect on how we each understand the concepts and any related principles for equality, diversity and inclusion.

What is publicly aired in terms of positionality across the virtual airing cupboard of the Internet is meeting in turn with mixed responses towards inclusivity, depending on the positionality of each reader. If we consider a rational approach to statements concerning embedding inclusive practice in $\mathrm{HE}$ then 'embedding inclusive practice' is treated as an objective. This approach overlooks the deeply subjective and dynamic aspects of inclusivity, as it is constantly being performed in each of our lives as 'flesh electric'. As such, in later chapters that examine some different roles in $\mathrm{HE}$, through postdigital positionality, the three tenets noted by Torres-Olave and Lee (2019), that: (1) identities are complex and fluid, (2) they are enmeshed in power relations and (3) they are contextually bound, will be considered as dimensions of subjectivity, deeply intertwined with technology and culture, with variable impact on what can be conceived as inclusivity.

\subsection{Where Objectivity Meets with Subjectivity}

One of the problems raised in The Labour of Words in Higher Education (Hayes, 2019a), was that rational policy discourse (McPolicy) assumes an objectivity that is difficult to question. The policy statements sound as if everyone should believe that this is how the world works, so to speak. Yet the attribution of human academic activities to non-human actors, such as institutions, buzz phrases and technologies is still written by someone, even if the identity of that someone is concealed. The same could be said of the programming, coding and design of data-driven systems where there is human involvement, but 
there are differences between the natural written language through which a human being expresses intentions and the activities of a computer interacting with data. The problem with describing what people do (and what they do with technology) as buzz phrases and even acronyms of those buzz phrases (e.g.TEL) is that this objectifies aspects of human labour and behaviour. Human subjectivity, creativity, emotion and reflexivity are rendered into a marketable item that might also be objectively measured and evaluated. Thus, people become referred to as if they were objects, not human subjects, through 'reification' (Lukács, 1971). Certain terms can gain a life of their own as they become adopted and imbued with particular qualities.

The idea of a 'circuit breaker' lockdown is an example that has been frequently discussed by politicians (as a more radical alternative to Covid-19 lockdown policies that focus only on regions). Now widely reported by the media too, people are being asked to believe in the circuit breaker, on the basis of how many lives may be saved (Gallagher, 2020). Thus, a phrase that once applied to an electric switch designed to protect a system from excess electrical current, overload or short circuit, has taken an emotive shape. Those who are unsure of its value in the longer term can be accused of letting more people die. This risk though depends on other factors including the trajectory the virus takes, as well as the vulnerability of those who come into contact with it.

A reification of language is not unlike algorithmic activity by a computer when people become referred to as objects. Recalling observations on computers from Mark Poster (1990), where 'identity remains part of the disciplinary protocol of the field' an important part of this debate is to question what humans hope to preserve in terms of their subjective human content. This is a pressing consideration amid increasingly intimate digital interactions between data-driven computing systems and their role in our private and public health arrangements and interactions. Academic work is often deeply personal and self-defining with individuals committing many unpaid hours to develop what they do with their students, colleagues, external collaborators and in administrative and leadership roles. If such labour is discussed as disembodied activity in HE policy, it becomes alien to the individuals concerned. Such a rationality becomes irrational if it then limits the scope of these endeavours. If agency is also given to terms (and not to people) this moves HE policymaking further away from genuine conversations on positionality. Hall argues that 'there's no enunciation without positionality. You have to position yourself somewhere in order to say anything at all' (Hall, 1990: 18). On this basis, Bourke suggests that 'positionality represents a space in which objectivism and subjectivism meet' (Bourke, 2014: 3). Each of us could 'strive to remain objective but must be ever mindful of our subjectivities. Such is positionality, the acknowledgement 
of who we are as individuals, and as members of groups, 'and as resting in and moving within social positions' (Bourke, 2014: 3). This requires reflexivity regarding how as individuals we each relate to an interplay of wider culture and technology, how we shape it and are shaped by it, in a postdigital age.

\subsection{Practicing Reflexivity Could Be Tricky for an Algorithm}

The challenge then is for HE institutions to find routes that move away from McPolicy and towards a reflexivity where new discourses concerning diverse postdigital subjectivities might be critically explored in relation to inclusivity policy. It is important to self-test one's own stance and assumptions and to consider when subjective 'self-descriptions' from those being discussed, may be more appropriate to include as narratives, than to write objective rationalities that ascribe an 'experience' to them (Argenton, 2015: 921, Hayes \& Jandrić, 2018: 127). Then there is the question of how such human critical reflexivity applied by people to the choices of language that they use might ever be enacted similarly by an algorithm? Eran Fisher (2020) in her chapter: Can algorithmic knowledge about the self be critical? raises the point that it is natural language that 'allows reflexivity' and the reasoning 'to reflect and examine the self and in turn transform the conditions of possibility of observed behaviour'. Humans can behave anxiously and identify hurtful behaviour through language, interpretation and reflexivity, but:

The algorithmic episteme represents a collapse of that constructive space between theory of the self and the performative, actually existing self, as well as an impossibility to communicate in natural language. (Fisher, 2020: 117)

Fisher (2020) places this reasoning within the subjectivities that have characterised different forms of capitalism, where:

- industrial capitalism moulded a subjectivity that realizes itself by means of hard work, obedience, diligence and frugality (Gramsci, 1971).

- consumer capitalism moulded a subjectivity that realizes itself by means of consumption, hedonism and individualism (Bell, 1976).

- we might now ask how informational, digital, network capitalism moulds a subjectivity that realizes itself through publicity, exposure, communication, sharing and surveillance (Fuchs, 2011, van Dijck, 2013, John, 2016) (practices that create the raw material to produce algorithmic knowledge: data), and through delegating the understanding of the self to technological systems, the underlying rationale of which remains completely opaque and inaccessible for auditing through natural language (Fisher, 2020: 118). 
The new algorithmic self in this conceptualisation is rendered into 'data patterns':

The algorithmic episteme suggests that we cannot say what is similar between individuals except that they show a similar data pattern in a given context. Two people showing similar data patterns on Amazon, for example, might be sociologically very different. (Fisher, 2020: 118)

Thus, we have a point of connection here between George Ritzer's description of our lives as con(pro)sumers, where we are exploited for our labour as we produce copious data and feedback for companies and agencies (such as Amazon, Facebook and news channels) all free of charge (Ritzer, Jandrić \& Hayes, 2018). This is repeated across all manner of data-driven platforms when we are busy commenting on, and cancelling, what others are saying as we reinforce echo chambers across the virtual airing cupboard. How can we even know what proportions of our human activities have been captured, sorted and classified for use by others elsewhere? Regardless of how each of us may perceive ourselves, in terms of personal identity, we can find ourselves being branded and pigeon-holed (through opaque processes) by the online activities we undertake. As Fisher points out:

During the 2oth century, a person might feel that she is part of the working class, or part of a gender group. Such ascription to a social category did not imply that everyone belonging to that group is identical in every way, but rather that anyone belonging to that group perceives herself as identical in aspects that are politically significant, for example, suffering from similar forms of discrimination, or sharing economic interests. (Fisher, 2020: 118)

Rendered into data 'promoted by the algorithmic episteme', not only do 'we have no way of knowing ourselves by ascription to a social category' this also 'threatens to undermine and deconstruct the foundations of political action' (Fisher, 2020: 118).

Therefore, where before:

mass media created categories of identity that could be spoken of with natural language, understood theoretically, be subjected to critique and resisted through political action. (Fisher, 2020: 118)

Now we seem to be in territory where: 
Digital media, in contrast, categorizes individuals based on data patterns which cannot be understood with natural language, spoken about or critiqued. (Fisher, 2020: 118)

Alongside these observations, in HE policy there seems to be a passive reinforcement of these troubling trends. It's time then to open up the institutional airing cupboards that store data on inclusivity and to critically connect university 'established' practices with the many implications arising across 'the entire ecosystem of connective media' (Fuchs, 2011).

\subsection{Making Associations of One Kind Can Risk Missing out Others}

The problem of institutional airing cupboards that gather data in isolation from the arguments above is realised when policy for inclusive practice is based on some associations about people's characteristics, but not on others. Taking as an example an experimental official statistic introduced in 2019 by the UK Office for Students (OfS) called Associations Between Characteristics of Students (ABCS), this set of analyses seeks to better understand how outcomes (including access to $\mathrm{HE}$, continuation in $\mathrm{HE}$, degree attainment and employment outcomes) vary for groups of students 'holding different sets of characteristics' (Office for Students, 2019).

We define groups of students by looking at a set of characteristics so that we can determine the effect of not just one characteristic on an outcome, but the effect of multiple characteristics. (Office for Students, 2019)

Recalling earlier discussion surrounding bias, (Liesch, 2020) argued that: 'we cannot count the number of ways that dimensions of identity intersect in a given person at a given point in time. The world is waking up to the fact that we cannot train the bias out of anyone.' Based on such arguments can we really count the 'characteristics' about anyone then either, or indeed 'define groups of students by looking at a set of characteristics'?

Whilst making associations of this kind may inform some general trends, it risks overlooking many other aspects of each individual student's postdigital positionality that are important or defining for them, rather than rationally determined via pre-defined generic characteristics. In HE, students are encouraged to work with critical and interpretive processes, to make ethics applications for the research studies that they undertake involving human participants, and to be reflexively responsive as to how their personal values and bias may influence their dissertation outcomes. The rational approach of ABCS seems a somewhat irrational way to be objectively measuring the 'multiple 
characteristics' of these diverse students, when as teachers and researchers we are actively encouraging each of our students to do the opposite in their own studies, i.e. to be critical, self-reflexive, subjective practitioners in their discipline. As Collini (2018) has questioned: 'does marketisation threaten to destroy what we most value about education?' and 'does this new era of accountability distort what it purports to measure?'

Another interesting connection to throw into this debate concerns the interpretations that are made by humans or machines concerning 'fairness'. The next example illustrates rather well the importance of taking into account how human subjectivities, and indeed student futures, now intersect with both technology and culture, with implications for inclusivity agendas. How any technology is introduced into any existing culture requires careful thought, yet the furore caused by use of an algorithm in the UK in the Summer of 2020 to grade A-level examination results indicates that multiple considerations were not taken into account. This is a topic that I will return to a little later in this chapter, but it is worth noticing here that there are similarities between adopting a methodology such as ABCS as laid out by the OfS, and the problem of the 'algorithmic episteme' (Fisher, 2020) that was let loose to determine grades, but then quickly 'scrapped after almost $40 \%$ of A-level results were downgraded from school teachers' predictions'. The UK Prime Minister, Boris Johnson, explained to schoolchildren affected that 'their grades were almost derailed by a mutant algorithm', whilst Stian Westlake, the CEO of the Royal Statistical Society (RSS) said that:

the 'colourful phrase' did reflect the fact that ministers, officials and students 'were surprised by the results that it generated'. But, he said, 'the algorithm wasn't a mutant or a freak of nature. This was something that could have been foreseen'. Mr Westlake, a former adviser to the Universities Minister, said the results were 'a predictable surprise' because of the demand that it reduce grade inflation. 'The fact that this could have produced a lot of inaccuracy, which translates into unfair grades for individuals, that was known', he said. (Manthorpe, 2020)

Ofqual, the exam regulator said that there were instructions from ministers to them 'to keep grade inflation down, which meant students' results would have to be downgraded from teachers' predicted grades, which tend to be higher than actual results' (Manthorpe, 2020).

There were further comments from Mr Westlake on 'the need for transparency in the creation of algorithms, not only because it helped prevent errors, but also because it allowed a public debate about their aims': 
I think the really important lesson from this is that we can't treat statistics as a holy grail, he said. We need to prepare them with transparency, we need to make sure we understand the assumptions that are going into them and we need to make sure that we use them in the right way. If you've got statistics that only have a certain degree of accuracy, as for example the A-level adjustments did, we can't pretend they are more accurate than they really are. (Manthorpe, 2020)

Fisher (2020: 119) has argued then that 'the algorithmic episteme' is problematic because it undercuts the critical faculties inherent in narrative, speech and inter-subjectivity'. As can be observed so readily through cancel culture, people use these faculties to greater or lesser effect, as they post opinions in the virtual airing cupboard. Drawing on Habermas (1972), Fisher (2020: 119) points to the reflexive experience that 'is the core of the practice which emancipates individuals from being an object and allows them to develop a subjectivity'. As such, this is a practice that has to be controlled and done by the subject. This in turn has implications for how university inclusivity policies discuss human characteristics, digital technologies and what can, or cannot be controlled now within HE institutions.

\subsection{Visible and Invisible Processes of Interpellation in the Postdigital Airing Cupboard}

Postdigital positionality recognises that dimensions of identity intersect in endlessly fluid ways for any given person, at any given point in time. If, as Torres-Olave and Lee (2019) point out, positionality is constructed around: complex and fluid identities, enmeshed in power relations and contextually bound, then as intersectional factors (such as gender, race, ethnicity, class, age, nationality and sexuality) come into play across the digital mechanisms discussed above, the 'flesh electric' is bringing countless, subjective variables into play.

The selecting of objective characteristics about any individual (defined by either humans, or algorithms) to base recommendations on, can therefore be a risky approach. If I sit browsing on my iPad and I find that on YouTube I am offered music suggestions based on what I have already listened to, then I can take these or leave them. If unseen data is gathered without my knowledge and an algorithm entrusted with decisions that alter my healthcare, employment prospects, or my child's route into university, then these are different matters. It could be time for me to leave my laptop and join the students taking to the streets to protest. The use of data on a school's historical performance to inform algorithmically determined grades saw the work of individual students become 'lost in the statistics'. The disproportionate effect 
for high-performing students at under-performing schools in poorer areas caused much anger with many people arguing that this reflected the 'wider biases of the UK's education system' (Porter, 2020). However, using teachers' predictions can bring problems too, including potential racial bias. Therefore, rather than using data about school performance alone to head off grade inflation, use of data about hidden bias to counteract societal injustice, alongside lots of different techniques could help to counter the bias present in teacher assessment too.

Ultimately, there is the issue too that 'exams were never a great metric for learning or success anyway' (Katwala, 2020).

There are countless different postdigital scenarios like this, where human and technological power relations are at play, as characteristics of humans are rendered into data and ascribed to a social category. As Fisher has pointed out, there is no way of knowing ourselves in this opaque process and as such it 'threatens to undermine and deconstruct the foundations of political action' (Fisher, 2020: 118). One of the problems that data-driven digital platforms present us with (alongside the many opportunities that they bring too) is that, as digital media interacts with wider culture (both online and offline) we are each continually confronted with ideas for us to either accept or reject. As I am browsing different websites, some perspectives may matter more to me or to other people - depending on individual postdigital positionality. However, this can lead into both visible and invisible processes of interpellation that human subjects (who bring their own personal embodiment of power relations and personal values) can find that they either wish or need to respond to. As I have selected examples to refer to in this book, I am aware that I have found these through online searches that often pick up stories from popular news media, but I have also added my own search terms. Alongside browser activity that I cannot fully see in terms of programming, my searches written in natural language were chosen by me. Therefore, postdigital activities bring collective and performative forms of bias and preferences.

Interpellation, understood as processes of encountering cultural values and internalising these, includes ideologies that 'address' people and offer them a particular identity which they are encouraged to accept (Althusser, Louis. 1971). The ways in which certain attitudes are presented and the routes through which these values can now travel into our inboxes or browsers are many. The process of accepting or not accepting a particular culture's given attitudes can quickly alter a person's standing or positioning, placing them in certain power relationships. To give a brief example, author J K Rowling has experienced huge success through the Harry Potter works, via her books, the movies and huge online followings, but she has also recently experienced backlash and cancel 
culture for expressing personal beliefs. Her letters and comments 'on transgender rights, including examples of where she thought demands by transgender activists were dangerous to women' have been 'criticised by LGBTQ+ advocacy groups as divisive and transphobic'. The reactions online have meant 'two of the biggest Harry Potter fan sites have distanced themselves' from her saying that her views are 'at odds with the message of empowerment in her bestselling books' (The Guardian, 2020a). For those reading this book, reactions to the J K Rowling example will vary, depending on personal lived experience and positionality in relation to gender, but there could be other factors too that influence whether or not to 'cancel' someone, or something. There is a multi-directional fluidity to notice around this example, as people take varied stances concerning transgender rights, but also tweeting opinions on broader dimensions, such as generational factors:

'In terms of awareness and language, there is definitely a generational shift going on', says Finn Mackay, a sociology lecturer at the University of the West of England and author of a forthcoming book on female masculinities and the gender wars. 'We know that Generation Z, a marketing term used to define those born roughly between 1995 and 2003, are most likely to use different pronouns like they/them, or to identify as nonbinary, and they see these terms as a lot more fluid'. (Brooks, 2020)

Others, such as 'Lucy Hunter Blackburn, of the policy analyst collective Murray Blackburn Mackenzie', argue that 'talk of a generational divide must also confront the ageism inherent in much online discussion', adding:

This debate has become an excuse to parade some pretty ugly attitudes about the right of women over a certain age to have a public voice, and the value of older women's political views. An unflattering veil has been drawn back on attitudes towards older women, particularly it appears among younger men, despite the fact that polling shows that at all ages it's men who have views based more strongly on physical sex. (Brooks, 2020)

There will be other individuals and organisations who will be more reluctant to comment, but this may reflect different postdigital positionings concerning the risks that they perceive of falling prey themselves to cancel culture, or taking into account 'libel chill', reflecting an unease to speak publicly on some topics, if there is a risk of litigation. 


\subsection{Positionalities on 'Taking the Knee', Removing Statues and 'Clapping for Carers'}

Further examples of positionalities can be noticed in much recent media coverage of social movements like Black Lives Matter (BLM). The question of whether people 'take the knee' as a form of physical protest against racism and incidents of police brutality has been under debate. An action undertaken by American Football quarterback, Colin Kaepernick, who remained seated on the bench during the US national anthem on 26 August 2016 has led to a range of responses. Kaepernick said at the time: 'I am not going to stand up to show pride in a flag for a country that oppresses black people and people of colour' and later in the same year Kaepernick switched from sitting to kneeling on one knee (ввС, 202ob). Recently a rather different approach was taken by US basketball player, Jonathan Isaac, a forward with Orlando Magic and an ordained minister. He became the first National Basketball Association (NBA) player not to wear a Black Lives Matter shirt during the rendition of The Star-Spangled Banner and remained standing while his teammates knelt around him. He explained this contrasting decision to that of Kaepernick 'by saying that kneeling or wearing a Black Lives Matter T-shirt 'don't go hand in hand in supporting Black Lives Matter' and added: 'Black lives are supported through the Gospel' (Gillespie, 2020). The UK Home Secretary, Priti Patel has since expressed disagreement with the BLM protests, describing them as 'dreadful' and saying that 'she did not agree with the gesture of taking the knee'. She argues that there are other ways 'people can express their opinions' (Parveen, 2021).

These different interpretations of BLM reveal just some of the complex human differences and viewpoints that manifest across matters of racism, religion and sport, both online and offline, and become influential in broader public education on matters of discrimination.

Whilst recent BLM protests around the globe have raised a broader awareness of matters of racial discrimination, they have revealed further positionalities from authors who comment on complexities that are less 'aired' in the media. Gittos (2020b) points out that whilst 'the BLM culture war rages on, knife-crime victims continue to pile up'. Bringing to mind my analogy of the airing cupboard's most popular, easy-to-reach sheets, he adds that:

we only ever hear predictable arguments on two sides of a culture war. One side blames absentee fathers and other 'cultural factors' like violent music. The other side blames economic degradation and cuts to youth services. The men and boys who die in these incidents simply fall into the background. (Gittos, 2020b) 
Drawing on the work of Stuart Hall (Hall et al., 1978/2013), Gittos questions whether racialising these issues is actually the best way to help us understand them:

Where Hall understood race to be one in a complex web of factors influencing the police too many today narrowly focus on racial disparity in the justice system and its supposed roots in individual prejudice. This can obscure rather than clarify the issues at stake. (Gittos, 2020a)

Referring to the Macpherson Report (1999) that stated, in the case of the Stephen Lawrence murder in the UK, that the police investigation was 'marred by a combination of professional incompetence, institutional racism and a failure of leadership', Gittos emphasises that this interpretation of 'institutional racism' was based on 'unthinking assumptions held by individual police officers'. However, as a definition, it was a departure from the 'institutional racism' described in Hall's analysis in Policing the Crisis (Hall et al., 1978/2013). Hall's argument was that the institution of the police had been weaponised in the course of class conflict, which disproportionately affected the black working class. This important change in the meaning of 'institutional racism' sets the context for the fixation on racial disparities in policing (Gittos, 2020a).

This suggests therefore that, whilst individuals are 'cancelling' each other online over different isolated gestures and comments of all kinds, there are also deep and multifaceted inequities that play out across institutions, historical structures and cultures and the programming of technologies alongside. The 'online sheets' in the virtual airing cupboard reveal current and popular arguments underpinned by the opaque platforms and data that deliver these to our browsers and phones. These intermingle too with content in newspapers and what is broadcast through our televisions, like an episode of Britain's Got Talent (BGT) when dance group Diversity performed a routine inspired by Black Lives Matter:

It depicted a white police officer kneeling on the Diversity star and temporary BGT judge Ashley Banjo, echoing the killing of the unarmed black man George Floyd in the US. The group all took the knee before the start of the song Black Lives Matter by Dax, which includes the lyric 'I can't breathe', the last words uttered by Floyd. (The Guardian, 2020b)

Amid many complaints, criticism and the praise for the performance, a response to the backlash, was posted on Instagram by Banjo: 
In the present moment though there is still so much to say... But I will just let this performance say it for me. For the thousands of supportive messages of love and inclusion - thank you. And for the thousands of messages of hate and ignorance I've received - thank you... You highlight exactly what needs to change and why this was so important to me and the rest of [Diversity].

Others, such as Historian David Olusoga, have raised the problem of the platform of television itself and of the TV industry failing to promote people from minority-ethnic backgrounds to positions of power (Hirsch, 2020). Different personal expressions therefore cut across a range of digital platforms and broadcasting media, they receive a lot of attention in the virtual airing cupboard in relation to cancel culture but there also many links to physical expressions of support for BLM as well as examples of cancel culture. As illustrated by a postdigital example below, messages over mobile technologies mean different things to different people. Here in Figure 10 the occupants of this van parked on a hillside in Wales have chosen to display their support for Black Lives Matter by writing the words on a sign in the window of their vehicle. At least this is a form of communication they can drive to locations themselves. Once messages travel through the virtual airing cupboard we simply lose this control.

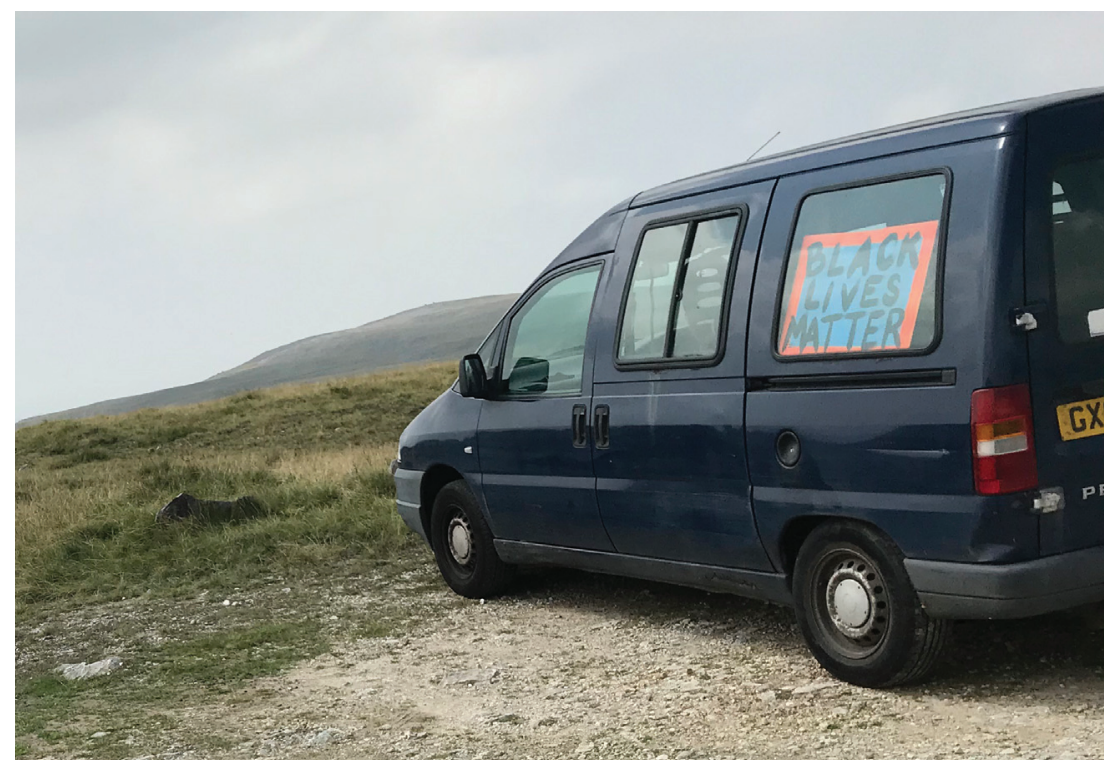

FIGURE 10 A Black Lives Matter sign displayed on a van 
Postdigital perspectives are valuable in that they draw attention to intersectional arguments and complexities that could be missed amongst the sheets of the virtual airing cupboard. As Chang (2020) observes, 'trending social media has indicated that there are currently two pandemics: Covid-19 and racism'. These are "key concerns in various parts of the world, particularly in nation states that experienced European colonisation and imperialism' (Chang, 2020). However, Chang highlights the 'deeper calls for systemic change, from policy to ideology to everyday practice' and also discusses critiques that have been 'directed at the privilege, positionality, and participation of Asian communities not only with \#BLM-oriented activism, but also in education and general society' (Chang, 2020). In raising complexities like these, Chang 'seeks to contribute to this critical discourse through a brief discussion of historical solidarity between Black and Asian activists and social movements' arguing that 'larger collaborations and legacies are often muddled amidst simplified Black/White binaries'. It is therefore important to 'explore some of the ways that historical Black-Asian solidarity can inform more intersectional and transnational analyses and pedagogies of Asian students, educators, and activists' (Chang, 2020).

The pandemic has seen further campaigns rapidly gather momentum, as people have sought to express solidarity with those healthcare professionals and key workers who have continued to remain active during the lockdowns.

The Clap for our Carers campaign, launched by Annemarie Plas during the first pandemic lockdown of 2020, was intended for UK citizens to express their gratitude for the contributions of essential workers, by clapping, cheering, banging pots and pans or raising applause from windows or doorsteps at $8 \mathrm{pm}$ each Thursday (Williams, 2020).

Whilst huge numbers of people stayed at home to work or found themselves furloughed during the lockdowns, key workers were thanked for continuing to leave the house. Messages of appreciation appeared in windows of businesses and homes alongside declarations from key workers themselves in their windows or on their cars, as can be seen in Figures 11 and 12. Unfortunately, what began as a voluntary gesture was accompanied by a rationality urging the public to express physical signs of appreciation. This quickly gained an angle that was less celebratory and more judgmental, as people started to be 'named and shamed' online for not clapping.

In another form of pointing out the 'dirty laundry' so to speak, this selfpositioning of some people as online critics to expose others that they perceived not to be demonstrating gratitude in this particular way, was evidenced through postings made to website Mumsnet. The woman who was criticised for not clapping from her doorway said: 'I just feel like I'm a total outcast on my previously friendly street now even though only one person posted it and only two others agreed' (Williams, 2020). 


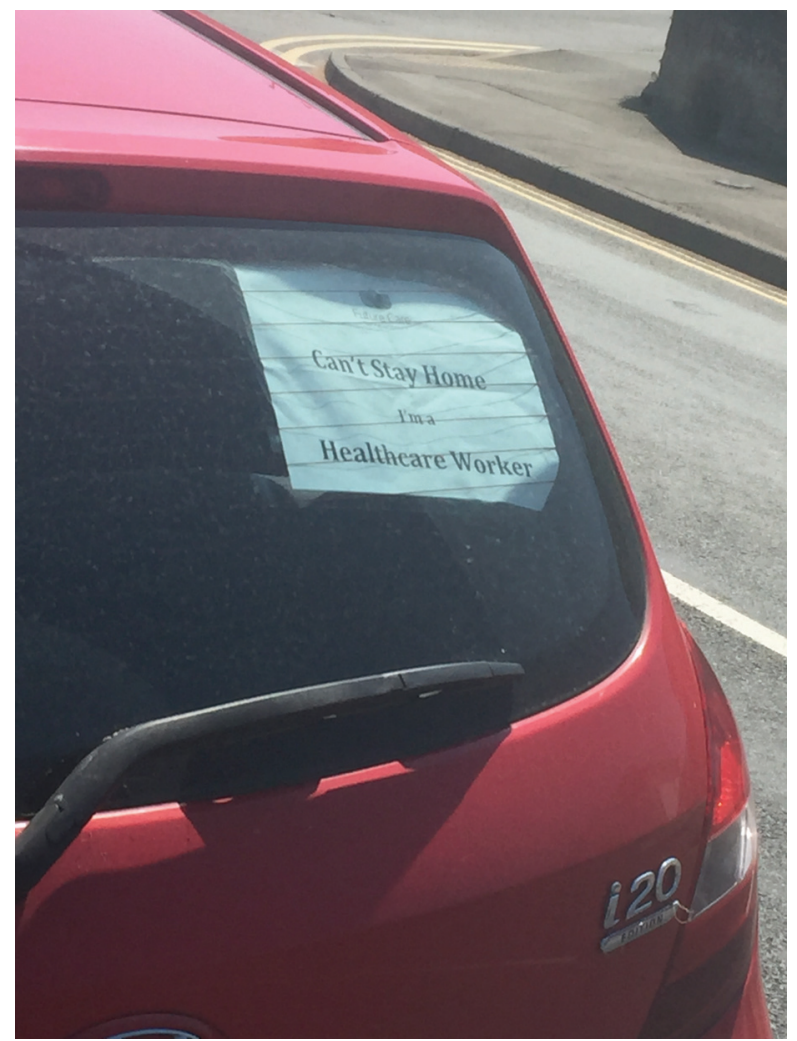

FIGURE 11

Healthcare workers identify their own positionality in their car window

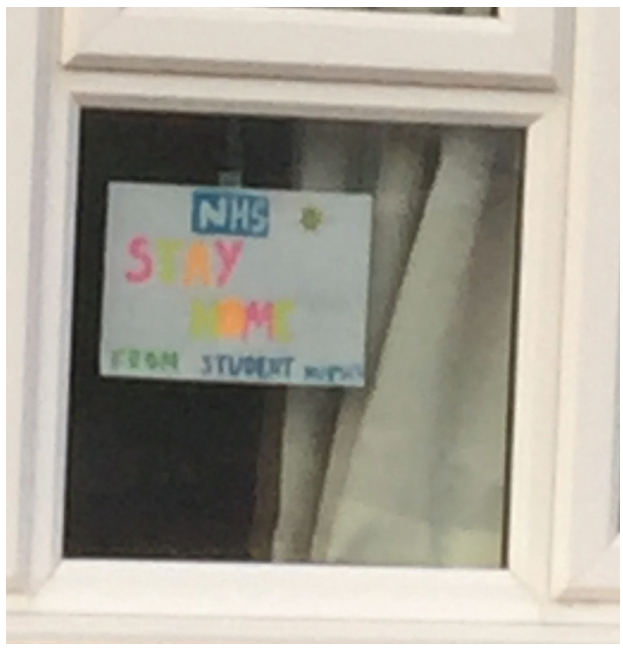

FIGURE 12

Student nurses urge people to 'stay home' on a sign in their window 


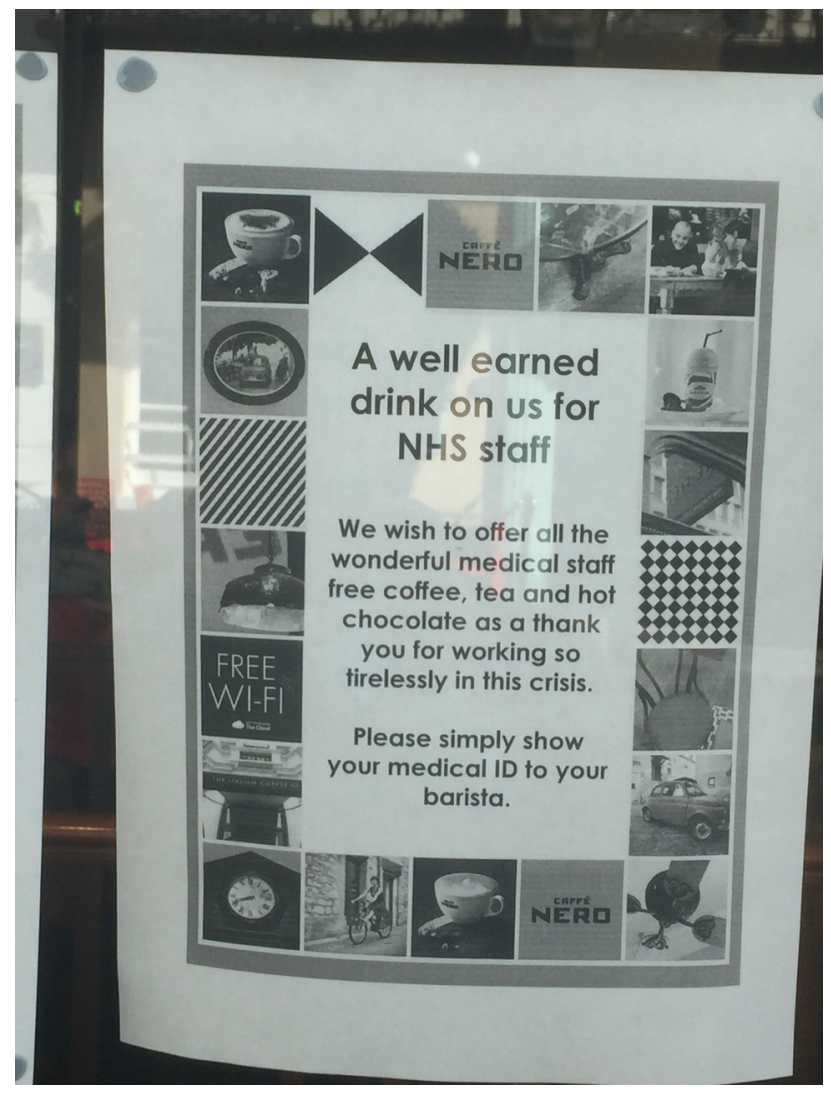

FIGURE 13

A sign offering medical staff 'a well-earned drink on us'

One should not overlook the irrationality of this rationality in this case, given that Mumsnet usually operates as an Internet forum to share mutual advice and support for parents. This seems to demonstrate how quickly a rationality (McClapping, if you will) became played out more irrationally, across augmented forums, as criticism via a website claiming to provide mutual parental support. Whilst some coffee shops were able to extend the offer of free drinks to key workers, as in Figure 13, others in the hospitality industry were forced to close if they were in districts with high infection rates. Some signs were broadly inclusive too of the key workers beyond medicine, such as teachers and shelf stackers (Figure 14).

\subsection{Reflexive Re-interpretation or Retrospective Re-alignment of Historical Culture}

Postdigital theory is concerned with identity norms of new contexts and those of old ones, as these now span both virtual and physical activities. The positionalities discussed above share dimensions of human identity that are enacted 


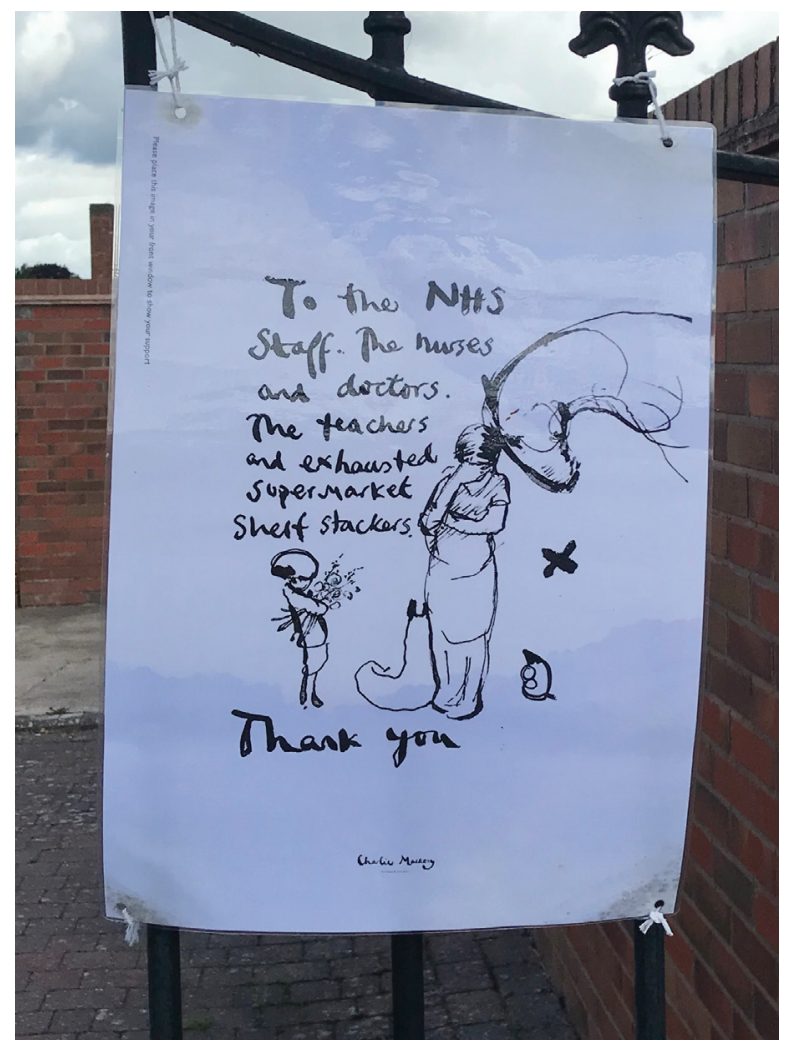

FIGURE 14

A sign on a gate thanking key workers

to sometimes include physical gestures or expressions made by the body, personal calls of judgment that are spoken or written, either online or offline, and material items, such as T shirts or stances on the toppling of statues.

Such interactions can clearly be noticed in calls during 2020 to remove statues where these may be linked to proponents of slavery or racist views. Some of the opinions seems to suggest that all manner of 'retrospective realignment' of aspects of the history of nations and institutions are needed where links to discrimination can be observed. Questions are raised about how far this can go, when history itself cannot be erased and museums and books remain. There are further debates about what then replaces statues that have been 'cancelled' from these former national cultures, such as an empty plinth. Or different arguments that 'confident forward-looking nations don't erase their history' (Hirsch, 2020). Other perspectives bring lifelong learning into this realm, to suggest that statues 'are an important educational tool that give those who don't read history books a reason to start thinking about the past'. Reinterpretation rather than removal is suggested to provide: 'a far more nuanced and complete version of their history' (Shearing, 2020). The National Trust in 
the UK commissioned a report aimed at illuminating the connections between colonialism and their properties, which opens with a pledge to honestly and openly share lesser heard stories that reveal the complexity of past, present and future:

Commitment to research, interpret and share the histories of slavery and the legacies of colonialism at the places we care for. Those histories are deeply interwoven into the material fabric of the British Isles; a significant number of the collections, houses, gardens and parklands in our care were created or remodelled as expressions of the taste and wealth, as well as power and privilege, that derived from colonial connections and in some cases from the trade in enslaved people. We believe that only by honestly and openly acknowledging and sharing those stories can we do justice to the true complexity of past, present and future, and the sometimes-uncomfortable role that Britain, and Britons, have played in global history since the sixteenth century or even earlier. (Huxtable, Fowler, Kefalas \& Slocombe, 2020)

As such, the National Trust has suggested reflexive re-interpretation can take place for individuals, as they visit these historic properties. Though what cannot be heard is the lived positionality voiced by those from the past who experienced discrimination, research like this is among many varied responses from institutions and museums to debates on equality, diversity and inclusivity. Examining these examples from different cultural institutions through postdigital positionality presents an opportunity for each of us to internalise many different perspectives and thus to disrupt the virtual airing cupboard of cancel culture.

Since the 'Colonial Countryside' review of the links between the National Trust and historic slavery, it has though come to light that $£_{150,000}$ of public and lottery money was used to pay for this review. Concern has now been raised that, alongside threats to free speech in universities, heritage institutions are trying to 'airbrush' history (Hope, 2021). Plans to fine universities where peoples' views are 'cancelled' are to be accompanied with the introduction of a 'free speech champion' linked to the Office for Students regulator. Steps will also be taken to ensure that heritage groups do not use public funds for political purposes in an attempt to defend the attempted rewriting of Britain's history (Gant, 2021).

As these cultural dilemmas continue to play out though, it is necessary to bring any new measures into dialogue with the technological problems raised earlier concerning disparities that arise through Human Data Interaction 
(HDI). There is an intersection where ethical examinations undertaken in the humanities to re-interpret reflexively human culture, need to inform us of ways that opaque data-driven platforms that conceal bias from view, might be reflexively re-interpreted also, to support not hinder, human emancipatory agendas.

At the start of this chapter Fuller described 'human' as a normative category concerning what 'self-described' humans decide to include, or exclude (Fuller \& Jandrić, 2018). Now that the performance standards of humans through history are receiving reflexive attention, it is time to include our non-humans in this endeavour. Computing systems as well as cultural artefacts are now active participants in our recent history, but they were never neutral nor unbiased because their actions passed through humans. Now a fluidity exists where human data passes seamlessly between technological devices, as well as via humans, yet identity is different (Poster, 1990: 147). Subjective human content is not the same as rational objective logic, despite how things may look on the surface. Maintaining distinctions between digital computing and the humanities as discussed by Gary Hall (2013) should not prevent active dialogue, at this intersection informing inclusive practices. This is now particularly important, at a time when museums, universities and all manner of organisations are making ethical, cultural changes to encourage greater inclusivity. The computer platforms and data participating in these processes needs to be subject to the same scrutiny that is being applied to humans. This is because the changing technologies that humans have both designed and developed have shared our political economic culture of capitalist values, which have also altered how universities are now perceived. HE has experienced a reduced autonomy over knowledge (Delanty, 2001) amid new forms of accountability (Power, 1997) and rationality (Ritzer, 1993). Human academic labour has become integrated both into global markets (Slaughter \& Leslie, 1997) and also the related technologies that support these.

\subsection{We Are Never Alone in (Self) Knowledge Creation}

These different positionalities reveal and require what Torres-Olave and Lee (2019: 5) describe as 'a constant renegotiation between self and setting'. They also argue that learning the identity norms of the new context, whilst still beholden to those of the old, requires a constant renegotiation between self and setting. This is an essential aspect of (self) knowledge creation' (TorresOlave \& Lee, 2019: 5).

The constant renegotiation between self and setting discussed by TorresOlave and Lee (2019) in an international researcher context, is applicable to these forms of interactions, as they take place for people between human 
physical experiences (such as disability) and virtual platforms with hidden aspects associated with them. When Torres-Olave and Lee (2019) argue that positionality is constructed around the three main tenets mentioned earlier, these complex and fluid complexities of identity creation, power relations and context can be noticed in the following example of TikTok. Here a clear interplay across self and setting in new data and politics driven online international contexts can be observed.

TikTok originated in 2014 as an app called Musical.ly, where youngsters 'would post short videos of themselves miming to pop songs. In 2017, Musical. ly was bought by the Chinese Internet company ByteDance and relaunched as TikTok with an already impressive number of around 680 million monthly active users (Fabiani, 2020). Since then it has become a defining social media app for young people to use in all manner of ways.

For example, in the case of 20 year old India Atkinson, who used TikTok to educate others about her disability, a rare condition meaning she was born without fingers on her left hand (McGarvey, 2020). Her videos explain humorously all the things that she is able to do, such as apply makeup, plait her hair and attend university. She has thus used a creative format to share her selfknowledge with society, and in so doing, she seems to have inspired millions of others to discuss disability. Yet the technological platform on which she is airing her positionality towards personal challenges and receiving much positive feedback, is at the same time the subject of controversy around censorship. Whilst TikTok is owned by a Chinese company called ByteDance, and not by the Chinese government, the app has been accused of censoring content that mentioned topics sensitive to the Communist Party of China, revealed in leaked documents (Fabiani, 2020). Whilst TikTok responded with a statement concerning their content moderation and data security practices (TikTok, 2019), there remains an absence of political content on the social media app.

Only two months later, Tiktok suspended the account of student Feroza Aziz for posting videos about the Chinese oppression of its Uighur Muslim population. 'TikTok claimed it did not suspend Aziz's account for its content but said instead her videos were removed due to a human moderation error' (Fabiani, 2020). Yet since then Netzpolitik.org have demonstrated how TikTok work behind the scenes to label political content as either 'not recommended' or 'not for feed', making it difficult to search, even to the extent of hiding videos of people with disabilities (Köver \& Reuter, 2019).

Thinking about moving within postdigital positions is now necessary so that each of us can acknowledge and find routes to resist the silent actors out there. In The Labour of Words in HE (Hayes, 2019a) I argued that the textual constructions written in natural language by humans can still alter how academic 
labour is perceived, when buzz words such as 'employability' are given agency linguistically to perform human tasks. It is no longer possible to separate out what is also constructed by algorithms and data-driven systems in conjunction with human decisions. Fisher (2020) raised the issue that algorithmic knowledge about the self will struggle when it comes to reflexivity, and the ability to be self-critical. This requires new levels of human subjectivity to be explored in relation to how we interact inclusivity in conjunction with data-driven systems, in these rapidly changing circumstances.

\section{3}

Postdigital Positionality in a Pandemic

This is quite a context to introduce further challenges into, but the pandemic has done just this during 2020. Before our eyes (as we look out over the top of our face masks) a global biological threat has played out differently in each of our individual lives, demonstrating the importance of paying attention to positionality in a postdigital context. This rupture to human existence and our existing political economy has provided (perhaps only briefly) something of a pause for reflection, with some authors suggesting this could be a potential 'portal' (Roy, 2020) and others arguing that 'the real world cannot be switched off or rewound like the German television drama, Dark (Suoranta, 2020) when 'reality violently breaks in' (Coeckelbergh, 2020). The danger is that the pandemic could produce 'a hypnotic paralysis which makes the crowd follow to its extreme every leading, suggestive impulse' (Simmel, 1950: 228, Suoranta, 2020).

The speed in which quarantine measures were enforced, led (again perhaps only temporarily) to some neoliberal rationalities being abandoned, such as the physical places that we once occupied before the lockdown. Many of the bastions of McDonaldisation could be found deserted across the globe. At the same time, there were reminders of the basic goods that mattered to people, as supermarkets ran low on stocks of toilet paper and other essentials (Figure 15) and people were asked not to bulk buy or limits would be placed on certain items.

Those people self-isolating were re-thinking aspects of their lives, as evidenced via their images, videos and comments across social media. All of these personal accounts from this historic situation should not sit in isolation from what might be learned for future directions in $\mathrm{HE}$ and beyond.

However, David Beer (2020) observes that this is also a challenging time to be writing. The combination of 'a weird mixture of lethargy and restlessness' makes it 'hard to concentrate on something for long enough to get into the depths of the issue'. Then there is the 'sheer speed that things are moving' 


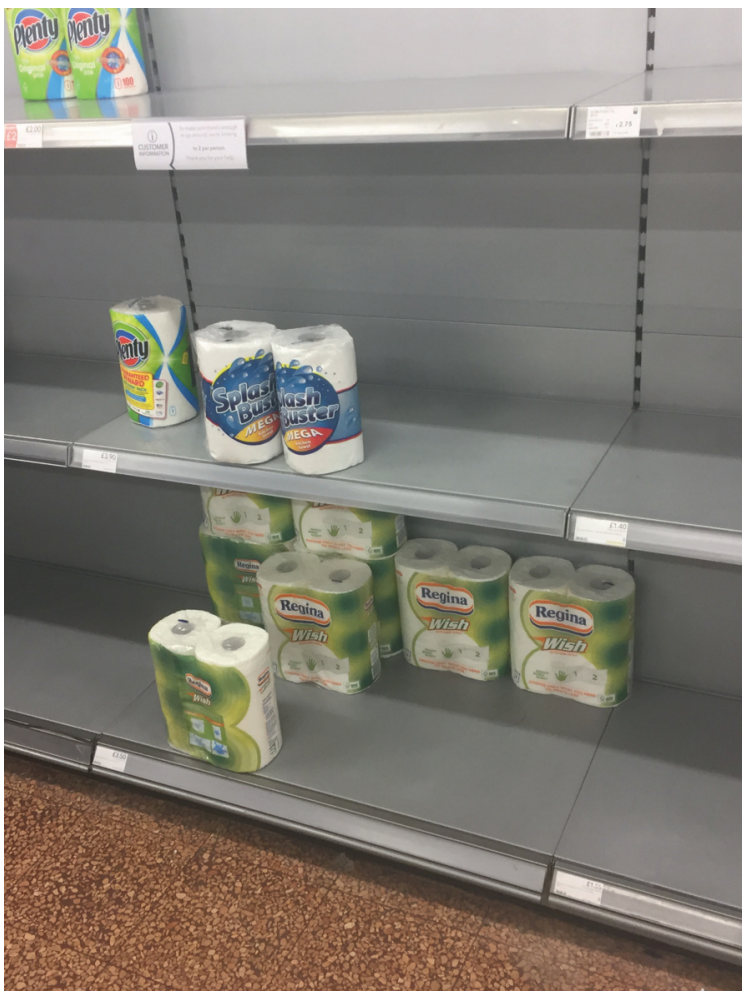

FIGURE 15

Supermarket shelves running low on stocks

where it is easy to 'get stuck describing a moment that suddenly, even a few days later, feels long-gone'. Finally, a 'sense that the thing I'd normally be analysing - society - will not be the same'. Beer comments further that 'unknowable differences are currently populating an imagined horizon':

It could be that increased networking, heightened and more visual social media connections, video links, mobile tracking and other features will persist, these will need to be thought through in detail. (Beer, 202O)

As I read this blog, I felt that I could closely identify with this honest account of postdigital positionality in a pandemic from a writer trying to make sense of changes in relation to technology and culture. Currently the Covid-19 pandemic and related lockdown policies have dramatically increased the use of online systems to support learning, health, welfare and entertainment. Some people were better positioned than others to access these digital devices, platforms, services and to employ the skills to interact through these. Globally and locally in different parts of the world, digital access, services, skills and opportunities are not evenly distributed (Traxler, Smith, Scott \& Hayes, $2 \mathrm{O} 2 \mathrm{O}$, Roy, 202O). Then there is an individual's choice not to use technology too. 
Such choices have tended to be 'framed using the rather binary concept of the digital divide where non-use is conceptualized as stemming from lack or deficit, drawing a line in the sand between digital haves and have-nots' (Thoren, Edenius, Eriksson Lundstrom \& Kitzmann, 2019: 325). Postdigital positionality challenges such simplified, techno-deterministic policy logic where 'individuals who do not use a particular technology (such as a computer or the Internet) tend to be portrayed as deficient in terms of a skill set, ability or socio-economic potential' (Thoren et al., 2019).

The pandemic has revealed disparities in developed, as well as less developed parts of the world, with the so-called 'digital divide' not only worsened through Covid-19 (Lem, 2020) but now connecting with many other forms of existing disadvantage across society. Whilst social distancing has, for some, involved home-based work, for others it has meant a loss of work. For some it has brought a break from travel, for others more desperate forms of travel (Roy, 2020 , Jandrić et al., 2020). Therefore, arguments like this one can apply only to some, but not all of the global population:

The shift to a locked-in world has accelerated the acceptance of identity as distinct from physical body or place. We still want to communicate, socialize and play during this time, but have only a digital version to offer. Those constraints are forcing new expressions of selfhood, from the Zoom background used to express a personal interest or make a joke, to the avatars roaming rich, interactive metaverses. (Gabrielle, 2020)

It is interesting to contemplate though, that for some people, their sustained online presence may be developing into an identity that is overshadowing their physical identity:

In stark contrast to the masked, distant, de-individuated person we show outside our homes, something a little less than human. There are indications that this redacted version of ourselves is becoming something of a style. (Gabrielle, 2020)

Such arguments suggest that we may have 'pivoted', not just in how we conduct the work that we do online, but as people who are now more vibrant virtually than we were as physical humans. Yet for others who decide instead to adopt hoodies with built in masks, or even full hazmat suits for face-to-face socialising, such as Micrashell 'a socially responsible solution to safely allow people to interact in close proximity' (Micrashell, 2020) they may want to disagree. Even as commuting into physical workplaces and study spaces was abandoned (for a while) and people became their own technical support engineers, if they could 
continue working online, there was the question of trust alongside opportunities for employers to undertake surveillance. Therapy animals needed to be our own pets (if we had them), with dogs and cats taking their own part in our new home-based gig economy as they wandered across our screens or lay sleeping across our ever-warm laptops.

\subsection{McSocial Distancing}

In early 2020, when 'social distancing' and 'self-isolation' first made their way into our daily language and practices, a group of companies responded to these Covid-19 health guidelines by producing socially-distancing logos for their global marketing campaigns (Valinsky, 2020). McDonaldisation (Ritzer, 1993, 2018), where sections of society appear to embody a similar rationality to that of global fast food chains, seemed at this point to be alive and well. Nor was this move particularly surprising. Predictability is after all, one of the key principles of McDonaldisation theory, alongside efficiency, calculability, control and the 'irrationality of rationality' (Ritzer, Jandrić \& Hayes, 2018).

Humorous, distancing signs like the icons produced by McDonald's, CocaCola, Audi and Volkswagen offered a diversion to what (for some people) was

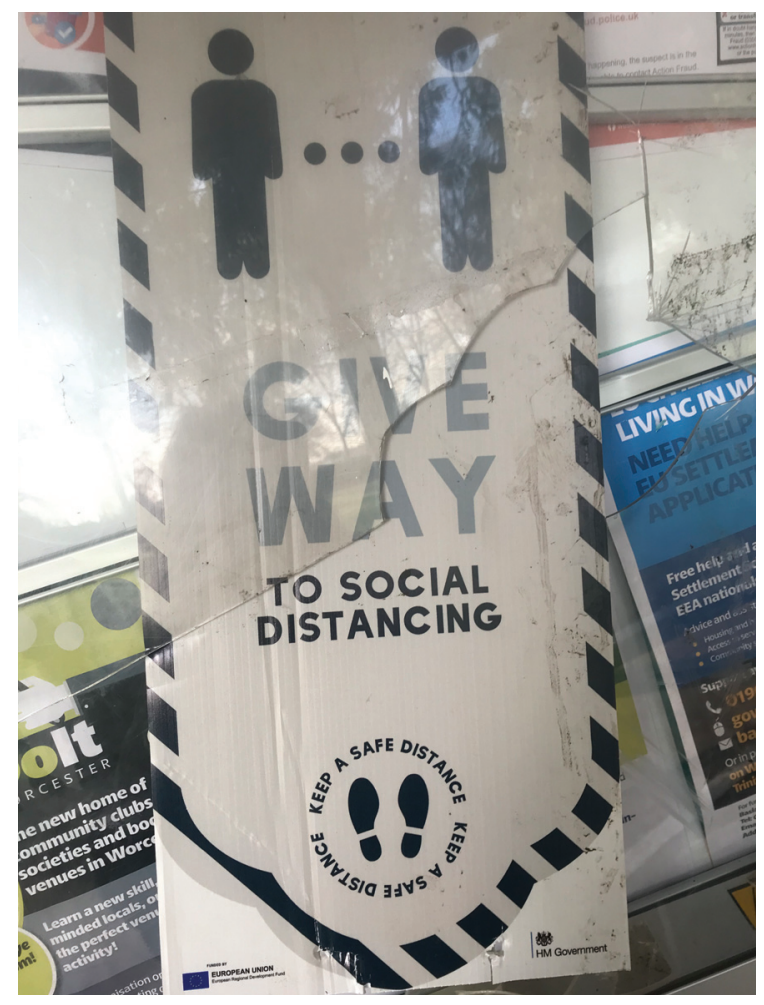

FIGURE 16

A sign urges people to 'give way to social distancing' 
already proving to be a tedious process. Public opinion on the logos was though divided. Were these images assisting the global effort by reminding people to distance from each other, or just making light of a serious matter? (Valinsky, 2020). Whichever of these viewpoints appeals, the production of static logos still plays its part in reinforcing a generalisation. It takes on a form of authority as a social construction when it is placed into phrases like 'give way to social distancing', as can be seen in Figure 16. Why not say, 'give way to other people'? As such, the process of social distancing becomes reified, to infer that it is experienced by everyone in a similar, predictable way. The many more individual aspects of social distancing and self-isolation, including the varied national lockdown timelines, separation from loved ones, personal grief, loss, quarantine, migration, and/or economic hardships experienced by so many people across the globe are rendered less visible (Jandrić et al., 2020).

\subsection{Symbols of Lockdown Positionality}

Yet a different form of imagery has provided us with a reminder of the more individual experiences of self-isolation.

Soon after lockdown was imposed, people began placing rainbows, teddy bears (Figure 17) and other personal, creative responses to social distancing in the windows of their houses or their campervans (Figure 18). Others encouraged their children to chalk messages on the walls of their homes or on the pavement outside.

Whether in support of key workers, health services, the Black Lives Matter movement, or simply to mark this unprecedented time in some way, images, statements and other items were placed within public view, outside pubs and on fences. Such symbols of lockdown simultaneously appeared through peoples' social media accounts, in newspapers and on television. This is but one illustration of what it means to live in postdigital times, where digital technologies, media and virtual relations of all kinds are inextricably intertwined with our physical human and social lives (Jandrić et al., 2018). Maybe it is also an example of how humans are not yet ready to be rendered invisible by digital advances, even when staying at home for their own protection from a highly infectious virus. However, whether they represent others, or draw attention to personal circumstances, the symbols of lockdown described above, have been chosen and placed on display in people's homes and personal contexts by individual people.

Even if some items were manufactured for others to buy and display, such as the rainbow posters praising workers in the health service, others chose to draw, knit or craft rainbows and place them in their windows, outside pubs (Figure 19), on gate posts (Figure 20) or share these symbols online. 


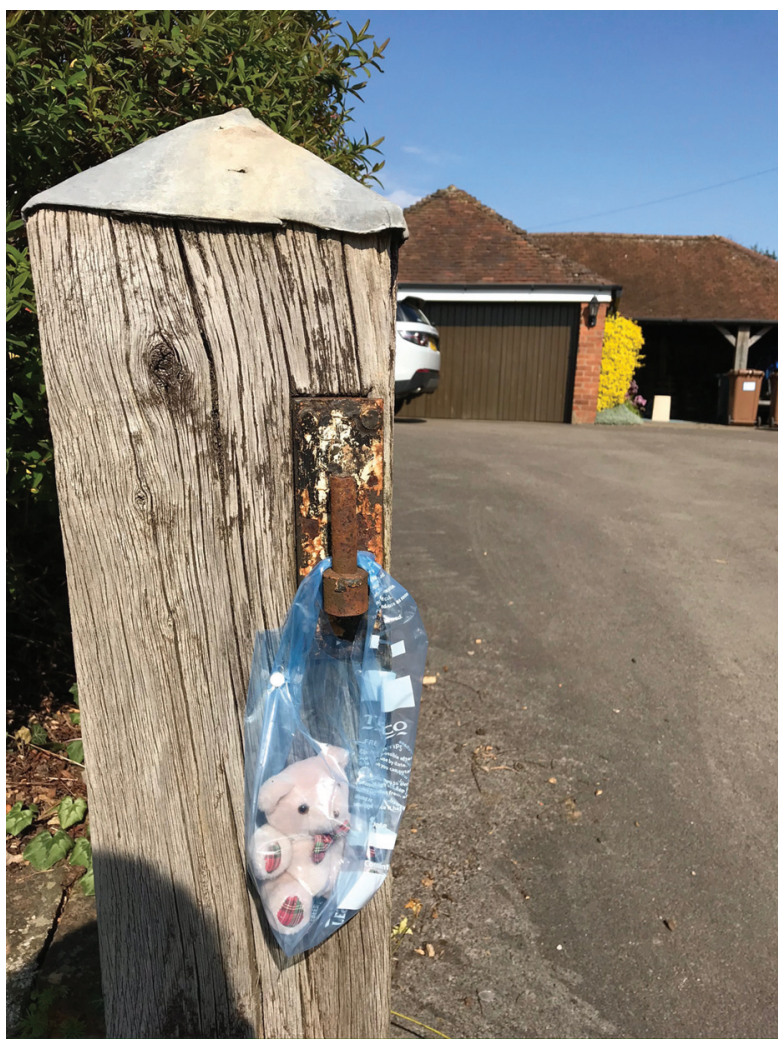

FIGURE 17

A teddy bear is left

hanging in a plastic bag on

a gate post as a symbol of lockdown

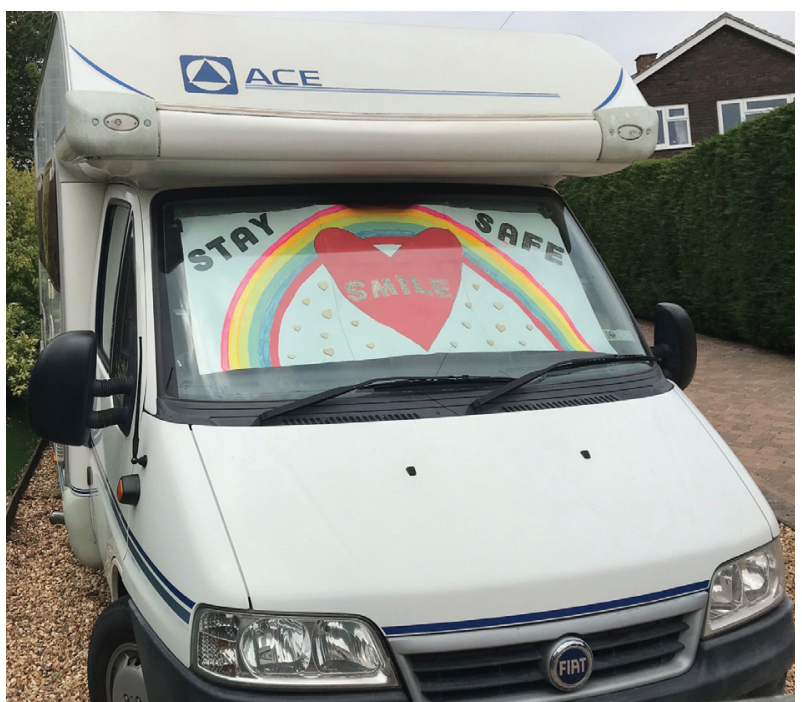

FIGURE 18 A campervan in a driveway displays a 'stay safe' and 'smile' poster 


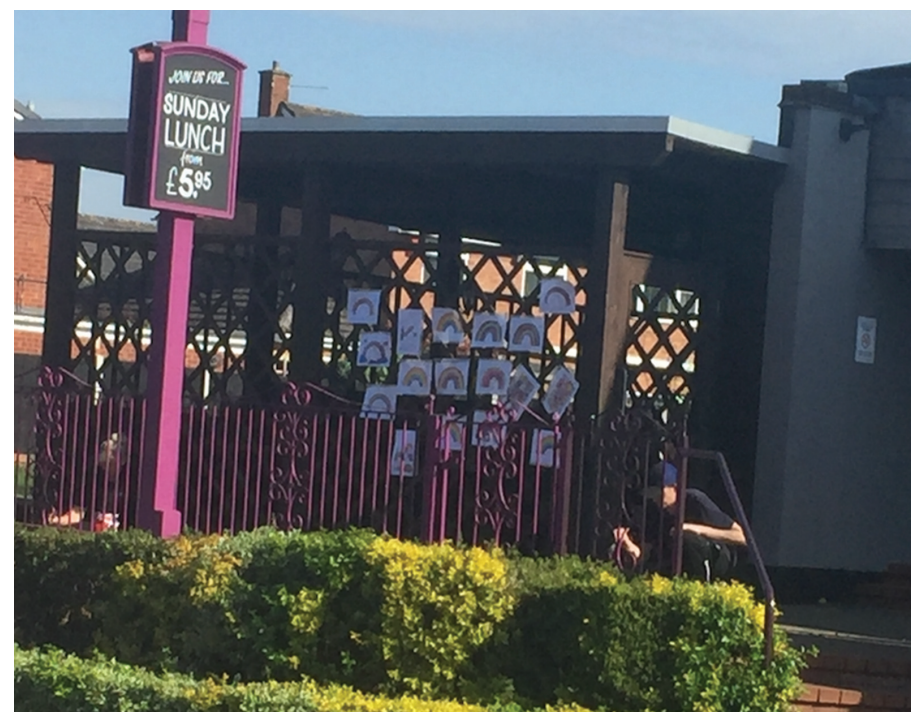

FIGURE 19 Children's rainbow drawings placed outside a pub

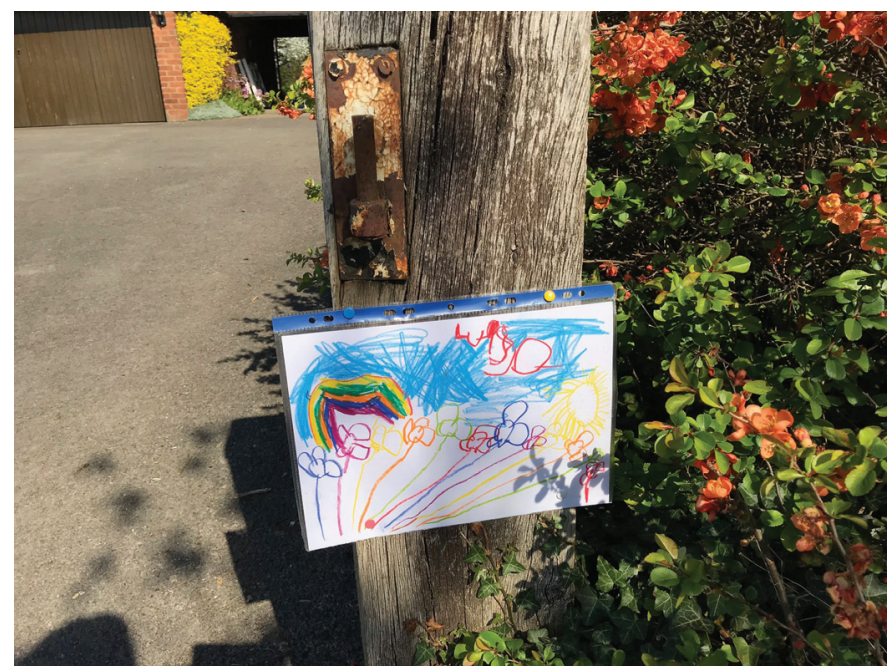

FIGURE 20 A child's rainbow drawing displayed on a gate post

Some went further still taking advantage of the empty skies to draw a message of hope in the form of an emoticon using an aircraft (Figure 21).

\subsection{Documenting the Voices of Covid-19}

The need to document the human voices of Covid-19 from all locations (on land or in the skies) and from all circumstances is a powerful route into appreciating 


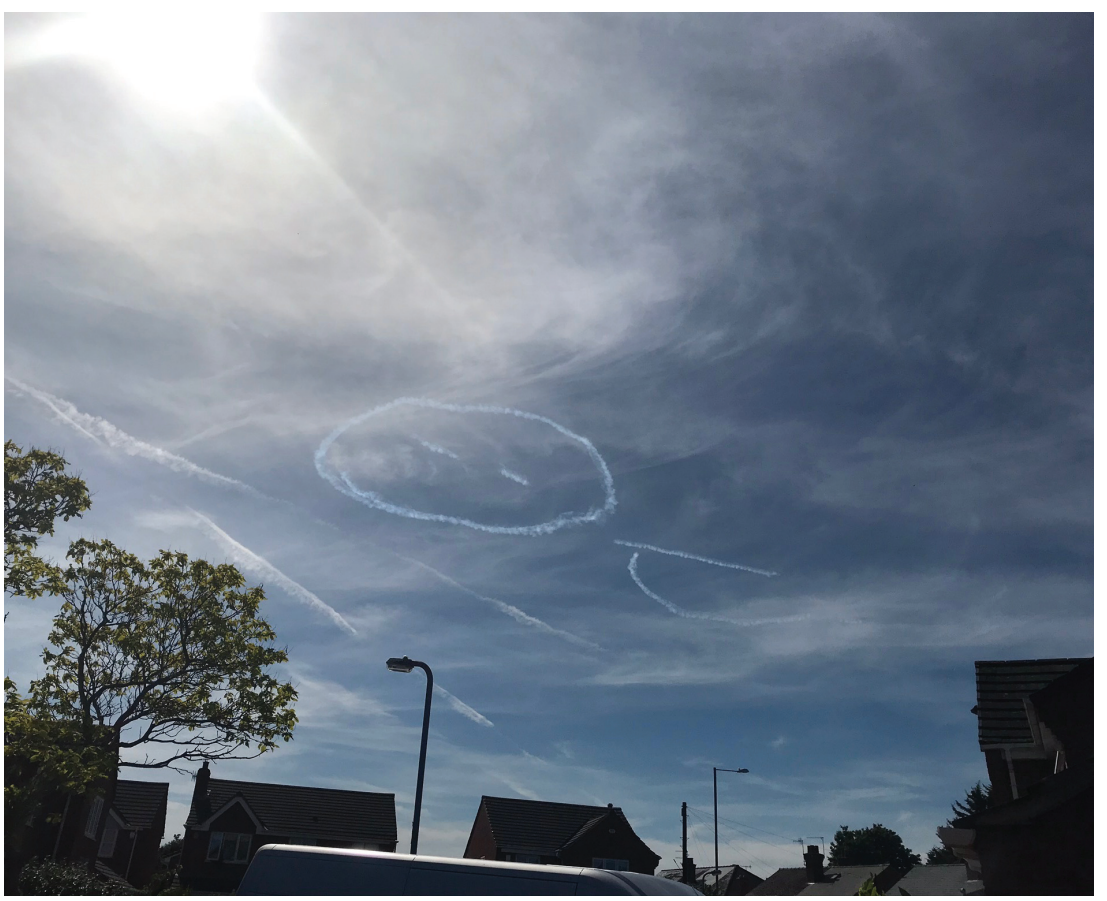

FIGURE 21 A pilot draws an emoticon of a smiley face in the sky above a UK city

the importance of positionality in a postdigital society. Research Councils are currently funding many scientific and social scientific research projects at the time of writing. One of these in the UK is the 'NHS Voices of Covid-19'. Funded by the Arts and Humanities Research Council (AHRC). 'It is supported by a diverse group of stakeholders including the National Health Service (NHS), the Trade Union Council (TUC), Age UK, the Stroke Association and many other health, community and heritage organisations. Other participants in the project include patients, policymakers, frontline NHS staff, young people and individuals with high-risk conditions' (AH RC, 202O). This blending of cross-sector stakeholders and the hundreds of volunteers who have undertaken the actual recording of these interviews demonstrates a strong interest in how diverse individuals are positioned during this historic crisis.

\subsection{Writing the History of the Present}

It is these deeply personal human narratives that are 'writing the history of the present' (Jandrić \& Hayes, 2020a). They are providing us all with deep insights into how postdigital change is experienced on an individual basis and through a global and local crisis. This process is powerfully illustrated through the broad collection of personal accounts shared by those working 
and studying in universities across the world as lockdown took hold between March-May 2020. In 'Teaching in The Age of Covid-19' (Jandrić \& Hayes et al., $2020 \mathrm{~b}$ ), the written responses to a Call for Testimonies sent out by Professor Petar Jandrić, to be published in the Springer journal Postdigital Science and Education was quickly retweeted across social network sites demonstrating the swift realtime response (Ryberg, 2020). Petar Jandrić, himself, describes his own positionality as he embarked on gathering accounts for this experimental collective article:

This general vision, without a clear idea of what I was doing, paved a bumpy road for the development of this collection. On 17 March 2020, I shared the Call for Testimonies on Postdigital Science and Education social network sites and I emailed it to the journal's mailing list. Based on my previous experience with similar calls, I expected to receive 10 to 15 contributions and produce a standard-length collective article aiming at postdigital dialogue (Jandrić et al., 2018) about the pandemic. Yet my call went 'viral', at least for academic standards, and a couple of weeks later, I had more than 50,000 words written by more than 80 authors. So how do I make sense of all that material? (Jandrić \& Hayes, 2020a)

'Teaching in the Age of Covid-19' is distinctive also because the request by Petar Jandrić for workspace photos from each author's home, if people wished to share them (and most did), has provided further dimensions from which to view this history of the present. Transitioning teaching and learning to be conducted entirely from home spaces over virtual platforms has though brought new complex considerations to examine in the balance between health, education, technology, diversity of individual circumstances and equality of opportunity.

\subsection{Pledging Open Sharing in Support of Learning}

Earlier, the pledge from the National Trust in the UK described a 'commitment to research, interpret and share the histories of slavery and the legacies of colonialism at the places we care for (Huxtable, Fowler, Kefalas \& Slocombe, 2020). The values of honest and open acknowledgement were mentioned to do justice to the complexity of past, present and future, including sometimes the confrontation of what is uncomfortable to admit. A human pledge refers to a solemn promise or undertaking to at least do something. Whilst not necessarily binding, it nevertheless can draw communities together and help further a common cause.

In terms of business and marketing, the word 'pledge' has been adopted as a brand name for a popular furniture polish which is advertised globally under 
phrases like: 'impress yourself, when it glistens, you glisten', alongside connotations that the act of polishing will 'renew' whatever you clean in this way and thus ourselves too (Pledge.com). In The Labour of Words in HE (Hayes, 2019a: 8) I pointed out the irrationality of rational HE policy statements by contrasting these with the discourse used in the marketing of products. Non-human products are 'humanised' in a manner that closely connects the properties of the product to the person using it. This intimate discourse of marketing sits in contrast with a linguistic tendency in HE policy documents, where teachers and students find themselves detached from their own skills, attributes and labour, which has been delegated to buzz phrases and technologies. This has impact on how included, or not, academics and students may feel in policymaking.

Pledge is a product manufactured by Sc Johnson who describe themselves as 'a family company at work for a better world' and like many companies at this time they are detailing their support of initiatives linked to public health during the Covid-19 crisis (SC Johnson, 2020). My reason for mentioning such dimensions concerning use of the word pledge, is to draw attention to complex intersections of culture, technology, language and political economy. The breadth of such interconnections impact on diversity and inclusion in postdigital society. For example, companies are also changing packaging and wording of products, if these appear to be derived from colonial connections or racial stereotyping. The change of name of Uncle Ben's Rice to Bens Original is one such example (Smithers, 2020).

Global companies and commercial platforms now have links to education at all levels. They have brought with them profitable interests, background culture and technology. They may have entered silently the academy through routes to support learning, research and marketing but it is important to recognise where these then align the public mission of universities with the private interests of digital capitalism' (Williamson, 2020b). McDonaldisation has already highlighted how rationalities that emerge around consumers and producers of products and knowledge both online and offline can lead into irrationalities. Alliances between $\mathrm{HE}$ and digital capitalism bring an interplay that impacts on what is written and what can feasibly be enacted through $\mathrm{HE}$ equality, diversity and inclusion policies.

Whilst postdigital is not a perfect term (Jandrić et al., 2018), it encapsulates this landscape of multiple and diverse 'actors' (that are not all human) that are now altering much of what may once have been described as 'established' or 'inclusive' practices in universities. People as individuals are now flesh electric (Lewis, 2020: 265) in that they embody and internalise values and ideologies from across the ecological landscape of digital capitalism. Whilst a can of Pledge can be attributed in marketing discourse with features closely linked to 
humans and that help them sanitise their homes in a time of crisis, it cannot itself demonstrate the personal self-reflexivity to undertake a solemn promise to contribute to collective change.

Responses within the global scientific community to share health and scientific research openly, has emphasised a widespread understanding of a need to respond collectively and also at many levels to the Covid-19 global crisis. This has further strengthened the existing alliances between commercial interests, science and education. The Open Covid Pledge was founded by scientists, lawyers, entrepreneurs, companies including Amazon, Facebook, Microsoft, IBM, Uber and other individuals in 2020 'to promote the removal of obstacles involving intellectual property in the fight against Covid-19' (Open Covid Pledge, 2020). In August 2020 the Creative Commons took over leadership and stewardship of the Open Covid Pledge to work with the steering committee with the hope too that continuation of this model might help to address other crises such as climate change. These are powerful global connections and aspirations that universities have connections with, but it is hard to observe where these are reflected in HE policy.

Inspired by the Open Covid Pledge, alongside recognition of the wholesale movement of education online during lockdown, the Open Covid Pledge for Research in Education has been formed. This growing community of educators and researchers are pledging to:

- Make our intellectual property openly and freely available to the world to support educators, students and decision-makers, to help educational organisations survive and thrive, and to build a fairer and more resilient education system.

- Where possible, openly license or dedicate to the public domain our intellectual property (Open Covid Pledge for Research in Education, 2020).

This is a promise that is made inclusively, with respect to the whole enterprise of education, despite lacking clarity on what the future may hold. The emphasis is on opportunities to learn, which despite the crisis, are perceived as constant, if not heighted presently. The instigators of this pledge point to the many 'new research programmes that have sprung into being' as 'established researchers have refocused their efforts' and argue that 'new evidence is emerging all the time about the impact on teaching practice, student participation and working lives' (Open Covid Pledge for Research in Education, 2020). This pledge then draws crucial connections together that are not, as yet, reflected in the policies that universities write concerning educational inclusivity: namely that our culture, politics, technologies, data, resources, health and education are interlinked, as we seek to address potential bias and inequalities post-Covid-19. 
As universities seek to tackle inclusivity at an institutional level, there are also opportunities to learn from each other at a global level (UNESCO, 2O2Ob).

Such learning can begin with open sharing of research and teaching resources, but this then requires an honest description in policy to reflect the diverse, postdigital positionalities of each of us. The principles of inclusivity cannot simply be 'plugged in' to universities, as the complex ecosystem that they now operate in, sits outside of institutions. It is driven by global aspirations alongside commercial, data-driven interests, but we cannot afford to overlook individual positionings within this picture, or this moves the whole endeavour in the direction of rational objectives, rather than human subjectivities.

Writing all of these implications into HE inclusivity frameworks may not, though, be too daunting a prospect, given that we would no longer be claiming to 'embed' so much into HE under the pretence of control. Rather we would be accepting that HE institutions now need to be plugged into these pledges of open sharing, in support of inclusive opportunities to learn.

\subsection{Viral Viewpoints and Inclusive Practices}

The relevance of these examples to this book on postdigital positionality in $\mathrm{HE}$ arrives via the many complexities that are now prompting people to act in terms of inclusivity. Where once access and participation in education was discussed at a largely social level, there are now more factors (and actors) to consider than interactions between people and their institutions of study alone. This has implications for understanding what influences inclusive practices in universities and what institutions can (and cannot) claim to be enacting, or indeed providing. It also has implications for how individuals experience what they believe to be inclusion.

Rational policy statements about what governments and educational institutions intend to $d o$, frequently overlook the agency of individuals and groups to act. The outcry over the A level algorithm in the UK is one such example. There is also the danger pointed out by Suoranta (2020), that amid the current levels of global confusion that we find ourselves in 'a hypnotic paralysis which makes the crowd follow to its extreme every leading, suggestive impulse' (Simmel, 1950: 228, Suoranta, 2020). Impressions can be given in the news media, and indeed in HE policy, that certain moral statements, feelings and actions are undertaken on behalf of all of us (Simpson \& Mayr, 2010). Indeed, many news websites have augmented news coverage, with deeply personal and emotive snippets of people's daily lives shared alongside breaking stories of disaster and events in different parts of the world.

In a postdigital society it is increasingly difficult to separate who (or what) is contributing to the 'viral' viewpoints that can be seen to spread rapidly across 
multiple platforms. Peters, Jandrić and McLaren (2020: 3) have referred to 'viral modernity', pointing to the association between viral biology on the one hand and information science on the other. They argue that this applies to 'viral technologies, codes and ecosystems in information, publishing, education and emerging knowledge (journal) systems'. The complex relationships between epidemics, quarantine, and public health management during the Covid-19 pandemic have further revealed this 'fusion of living and technological systems' (Peters, Jandrić \& McLaren, 2020: 3). During the Covid-19 crisis, moral judgements have intermingled with public health advice and misinformation 'infodemics' (Peters, Jandrić \& McLaren, 2020, Gregory, 2020, Peters \& Besley, 2020). Much has been written too, concerning post-truth and fake news in postdigital society which is transmitted virtually across multiple forms of media as well as in physical spaces (Peters, Rider, Hyvonen \& Besley, 2018).

After online headlines emerged stating that people's pets may carry the Coronovirus, further reports and images quickly emerged to claim this information had resulted in animals being physically thrown to their deaths ${ }_{7} \mathrm{News}$, 2020). In less dramatic images, homeowners displayed signs requesting that those passing by refrain from petting their animals in view of potential dangers of transmission through fur (Figure 22).

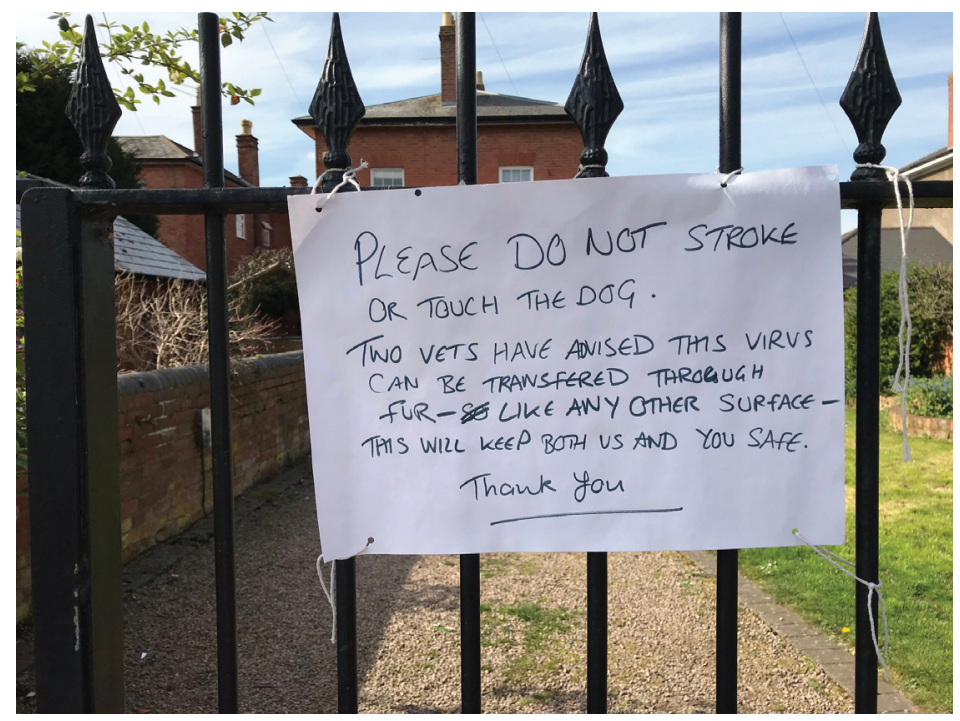

FIGURE 22 A householder urges people not to stroke their pet dog

If this appears bizarre, it is worth reflecting, that some surprising viral ideas have gripped society historically, well before the digital age and during times when diseases were rife. One example, 'the great book scare' was 'a frantic 
panic during the late 19th and early 2oth centuries that contaminated books - particularly from lending libraries - could spread deadly diseases'. Arising partly 'from a combination of new theories about infection and a distaste for the concept of public libraries themselves, Americans and Britons feared the library's easy access to what was seen as obscene or subversive books'. Legislation followed in the UK, with 'the law updated in 1907 with explicit reference to the dangers of spreading disease via book lending, and those suspected of having an infectious disease were forbidden to borrow, lend or return library books, with fines of up to 40 shillings for such crimes, equivalent to roughly $\$ 200$ today'. Thus 'the perceived danger of public access to reading material, it seems, can take as much of a physical as an intellectual form. (Hayes, J., 2019). For those of us still cleaning our shopping trollies with sanitiser, or teaching having been provided with face visors and disinfectant wipes for the books and the photocopier, this could now sound all too familiar. Annika Mann (2018) describes contagion as:

Both a communicable disease and its means of communication, a means that is transformed by the disease in turn. Contagion has been of particular interest to literary scholars and theorists because the term provides such an apt model for how language itself works, how meaning is transformed by its communication. (Mann, 2018)

At a time when humans were already grappling with an overflowing virtual airing cupboard, the physical communicable virus of Covid-19 has reminded us of the intimate relations between our physical bodies and our means of communication. Scientific remedies to aid us in defeating the pandemic may need a controlled temperature, rather like the physical airing cupboard, but there is a need to keep an eye too, on how this environment is connecting with the virtual cupboard. When on 8 February 2020 Adam Kucharski, an epidemiologist and author, wrote in the Guardian that: 'misinformation on the coronavirus might be the most contagious thing about it' (Kucharski, 2020) this was picked up the same day and quoted in a media briefing by the Director General of the World Health Organisation. Kucharski advises:

The best way to tackle these online rumours? Treat them like a real-life virus. (Kucharski, 202O)

They are also postdigital rumours because they do not remain online alone. Thanks to the contagion of language they take the form of any media of conversation. The human decisions to place an image of a rainbow in a window, tweet 
support for others, or 'clap for carers' (Williams, 2020) are personal motivations but are also interlinked with 'bioinformation' (Peters, Jandrić \& McLaren, 2020). This is information generated by multiple and diverse 'actors' (that are not all human) but may still influence how humans respond physically or virtually with empathy towards others, or indeed how they present their own positionality on all manner of issues across various postdigital platforms.

The warning of 'Don't Kill Granny' is one such example. Swiftly reported worldwide, this blunt slogan was aimed at young people in Preston, Lancashire in the UK. It was intended to warn them 'about the consequences of ignoring coronavirus social distancing rules - unwittingly taking the virus back home to vulnerable relatives and friends' (Day, 2020). It proved popular with Grandmothers but less so with others such as Callum Taylor who tweeted that: 'Many young people have lost elderly grandparents during this pandemic and are still grieving. Using the slogan \#DontKillGranny is utterly vile and insensitive! I would have expected better from a Labour run council!' (Taylor, 2020). There are also differences between the acts of empathy undertaken by individuals (however these might be influenced) and those rationally undertaken by either journalists, profit-making companies and government agencies, on behalf of others. Despite these distinctions, the voices and opinions from different sectors (with different vested interests) are now merging into a swirling mass of postdigital commentary, requiring some additional ventilation, perhaps.

\subsection{McInclusivity or Genuine Activism?}

Issues arise in terms of who (or what) speaks on behalf of other individuals and groups in crisis. The plight of migrants crossing the Channel between France and the UK is one such illustration. The ice cream giant Ben and Jerry's posted a response on Twitter to the UK Home Office plans to 'stem the latest surge in Channel crossings' by invoking tougher border controls and returning migrants seeking refuge in the UK to France. In tweets addressed to the Home Secretary, they wrote: 'Hey @Priti Patel we think the real crisis is our lack of humanity for people fleeing war, climate change and torture' adding that 'people cannot be illegal' (Brewis, 2020). The Home Office responded by calling Ben and Jerry's ice cream 'overpriced junk food' and as these posts were rapidly shared, the story played out to reveal different viewpoints within the public domain. At the same time, as 'scores of Twitter users praised the US company for speaking out', one person wrote 'Ben and Jerry: not all political heroes wear capes, some simply make amazing ice-cream and just seek to make the world a better place' (Brewis, 2020). However, other Twitter users revealed a different positionality, as they condemned Ben and Jerry's for their 'large scoop' of 'virtue signaling' served with 'grossly overpriced ice cream' (Swinford, 2020), for 
political 'pontificating' and alleged hypocrisy' (Brewis, 2020). Further Twitter users pointed out that not only do Ben and Jerry's not have to deal personally with the consequences of immigration, they are owned by Unilever, against whom 'a group of 218 Kenyan tea plantation workers have filed a complaint with the UN' (Brewis, 2020). At the same time, multiple suggestions for new flavours of ice cream were also posted, including 'Social Justice' flavor ( $\mathrm{HRH}$ the saboteur, 2020).

Not unlike the 'McSocial Distancing' logos, this example has played out to reveal a form of 'McInclusivity' that has both raised attention on the plights of migrants as a group and also trivialised the issue. What it hasn't done is explore how migration and inclusivity is being experienced through the individual perspectives of each migrant. Instead it has altered the discourse about migrants in different ways even to include discussions on how people shop for ice cream. It becomes necessary to ask whose rationality or logic is at play in anything we now read or view, bearing in mind that even a form of rationality itself must be theorised as fluid, regardless of where it originated from. In a global context where neoliberal forms of capitalism have come to dominate so much of how we live, this is experienced differently in developed and developing countries as well as in individual lives. Across television, print and virtual media, journalists deploy techniques to humanise the cases they report and to evoke empathy from readers, but not necessarily to enact solidarity at a political level (Varma, 202O). Varma contrasts this approach with 'radical inclusion' that actually 'begins with marginalized people's analytical perspectives' (Varma, 2020: 1) which reveal a personal positionality, rather than an institutional or company stance.

\subsection{McVaccination Programmes or Vaccine Alliances}

Examples like the Covax vaccination programme help to illustrate the difference between a personal positionality and a media, institutional or company stance, but also how these are mutually constitutive:

The relative obscurity of this vaccine program belies its critical role in the global battle against Covid-19. Indeed, covaX may well be the most important acronym of 2021. As vaccine nationalism rears its ugly head, it's the best - perhaps the only - bet on getting billions of doses to lowerand middle-income countries. (Lister, 2021)

In order to avoid a McDonaldised consumer culture and discourse dominating the distribution of vaccines only to those who can afford to buy them across the globe, coalitions are seeking to buy coronavirus vaccines in bulk and send 
them to poorer nations that can't compete with wealthy countries in securing contracts with the major drug companies' (Lister, 2021). covax includes the Vaccine Alliance known as Gavi and the World Health Organization (WHO) and is funded by donations from governments, foundations and multilateral institutions. However, as this report points out, secured does not mean obtained.

There are many more contextual aspects and hurdles too, such as capacity, logistics, funding, country and individual readiness, cultural and educational factors, to enable doses of vaccine to reach the individual human bodies of those who require them. The vaccine is after all a product making its way through a global consumer-based society where 'vaccine panic' has taken hold and:

The greatest challenge to global coverage is a 'me-first' attitude that's been criticized by global health officials. (Lister, 2021)

In terms of positionality and inclusivity, the spread of the virus itself has broad effects across different communities, now that vaccines have been developed. Individuals and countries across the globe find themselves confronted with new moral dilemmas. These require reflexivity to recall where serious delays in anti-retroviral treatments reaching continents like Africa for example led to catastrophic death rates from HIV and AIDS. Therefore an urgency to work towards the safety of all is competing also with national, economic, cultural, political and logistical priorities, and with the emergence of new variants that do not respect borders.

\subsection{Could the Pandemic Be a Portal?}

In terms of a more hopeful outlook there are other positions being taken on the potential responses that humanity might make, with regard to the pandemic. As nations entered lockdown, amid traffic ceasing, businesses closing and wildlife returning, some authors speculated on the 'work' of the virus in 'bringing the engine of capitalism to a juddering halt' (Roy, 2020). Certainly, it holds some appeal to envisage Covid-19 could be also 'distancing' humanity from the excesses of capitalism, ingrained forms of neoliberal rationality and inequalities. Yet whether 'the pandemic is a portal' that we might now choose to walk through 'ready to imagine another world' (Roy, 2020) is still up for wider discussion. Could humans be ready to undertake a 'global reset of education' to move away from the global conditions we have created 'that are hostile to our best interests and counterproductive to our collective wellbeing (Robinson, 2020: 7)? If so, then 'the battle of the decade', with respect to public 
education systems, may be upon us (Fullen, 2020). Fullen argues that 'since the 1980 s, education has become part of a system of stagnation' and one in which many students show a 'dramatic loss of interest'. He points to the significance of the pandemic in de-skilling each of us:

the pandemic brings a new context to us virtually every week. Thus, we are all de-skilled in this prolonged period of non-linear ambiguity. We are in a more complex world compared to any time in the past. From a change perspective, there is nothing so complex to solve than the situation we have at present times, and there is no indication that conditions will get better. (Fullen, 2020: 26)

In a collection of testimonies from academics and students from around the world, captured at the start of the lockdown (Jandrić et al., 2020), speculation of this nature was also on many peoples' minds. Authors suggested that 'this is a time when universities could embrace and offer something more emergent, sustainable and healthy', that 'the critical voice from the university might be crucial', but then again, a 'critical question is, will we be allowed by society to take that role?' In the struggle ahead, this is still unclear. At the time of writing, many school pupils have returned to their classrooms and playgrounds and these are very different in appearance to the ones that they left 6 months ago. Almost as soon as the new autumn term began though, schools were shutting again due to a rise in Covid-19 cases. In the UK Government, guidance for the return to schools emerged only days before lessons resumed, with this being described as 'insulting' to staff (Stubley, 2020).

Meanwhile universities were dubbed to be particularly 'unhealthy' as they proceeded to reopen their campuses as planned (UCU, 202O). Universities that ordinarily offer potentially life transforming changes to peoples' lives were being argued instead to risk 'doing untold damage to people's health and exacerbating the worst health crisis of our lifetimes' if the migration of over a million students across the UK should proceed as it usually would at this time of year (UCU, 202O). The argument that this movement of people following the 'A levels fiasco' (ввс, 2020b) and removal of the cap on the number of students that universities can recruit (Fazackerley, 202ob) now risks 'overwhelming some institutions and turning universities into the care homes of a second wave' (UCU, 2020). Since these comments, students have returned to universities across the UK. Within days of freshers' week, there are reports of thousands of students now entering campus lockdowns, and even feasibly being asked to remain on campus over the Christmas break. The students are being discussed as 'trapped' by a 'shambolic return to university' and questions being asked by 
students themselves as to why they were told to attend in the first place (ввс, 2020d). Such an emerging context, as Beer (2020) has commented, is hard for writers to keep up with. Given the direction that $\mathrm{HE}$ had been moving, in terms of measuring excellence across various areas, prior to Covid-19, it is hard to imagine what would currently be being 'measured'. There will however be much to compare in time and the rich qualitative data will be important to respond to. Meanwhile, speculation on a post-Covid-19 normal will continue.

An author from the collection of Covid-19 testimonies pointed out, though, that universities do need to invent new stories, new purposes and new identities - ones which can address the concerns of local communities and the global society' (Jandrić et al., 2020). Covid-19 has yielded vast numbers of research publications. In education, these currently range from practical advice on moving teaching online (referred to by some as a 'pivot'), sharing materials and tips, commentaries on mental health, the effects of working virtually from home and speculation as to what the 'new normal' means, amid the broader context that HE now needs to respond to. Prior to the lockdown, universities had left themselves little room for such debates (Hayes, Jopling, Hayes, Westwood, Tuckett \& Barnett, 2020). Strategies can be located for each new regulatory issue, but less so the ongoing authentic dialogues (Hayes, 2019a) that would avoid these, and the technologies or inclusion that they refer to, simply being 'free-floating' (Rikowski, 2003: 140). Detached issues may be perceived to enable an ease of measurement, but the nature of what $\mathrm{HE}$ is being asked to measure for regulation (Office for Students, 2018) has postdigital dimensions that currently remain overlooked.

\subsection{Circulating What Is Included in the Contents of the University Airing Cupboard}

Inclusivity in HE has long been perceived as a practice, culture or set of values by which diverse learners are admitted into a context where they can achieve their potential to succeed. The inference is that such achievements are 'driven' by universities to support social mobility:

Universities driving social mobility: we aim to create a future in which anyone with the will and potential to succeed, regardless of their background, has the opportunity to transform their lives through accessing an outstanding learning experience at a UK university. (UUK, 2O2O)

What universities are actually in a position to be able to 'drive' now, in terms of inclusion, is a key part of the postdigital positionality debate. Reflecting on this context, Traxler has argued that due to an: 
onset of pervasive and ubiquitous connectivity and mobility, profoundly transforming the production, ownership, distribution and nature of learning and knowing and problematising the role and status of universities and lecturers. (Traxler, 2020)

This is not so much about:

Inclusion of people from the outside world selectively invited into the higher education system but the inclusion of the higher education system into the world outside. (Traxler, 2020)

However, he has argued further that for the UK, Brexit has now intervened and been swiftly joined by the Covid-19 pandemic with both of these threatening to overturn a world of steady change and stable argument' (Traxler, 2020). Therefore, we have an opportunity for circulating the contents of the university airing cupboard, by opening it from all sides. The pandemic has intimately exposed the diverse contexts of students and staff, revealing differences and inequities in academic lives that cannot be contained within buzz phrases like 'the student experience' (Hayes \& Jandrić, 2018). These personal narratives bear little resemblance to the rational McPolicy statements analysed in The Labour of Words in Higher Education (Hayes, 2019a). Therefore, in the post Covid-19 HE context we need to revisit this language. 